\title{
Facilitadores institucionales y sociales para la gobernanza local de los riesgos medioambientales. Análisis empírico con municipios chilenos
}

Patricio Valdivieso

\section{Introducción}

La transformación de las condiciones medioambientales, la frecuencia de eventos extremos y sus consecuencias negativas en las condiciones de vida de la población justifican el esfuerzo de investigación por entender cómo están respondiendo los gobiernos locales al desafío y por conocer las barreras y los factores que facilitan una mejor adaptación (Panel Intergubernamental del Cambio Climático (IPCC), 2012; 2013).

Los riesgos de desastres naturales tienen que ver con factores que afectan el medio ambiente, tales como la contaminación, eventos geofísicos y el estrés producido por el cambio climático. En este estudio, el análisis de la gestión medioambiental y de reducción de riesgos de desastres (GMRRD) se refiere a las decisiones de los gobiernos locales sobre presupuestos, inversiones, y acciones relacionadas que tienen el propósito de proteger el medioambiente, preparar mejor a sus comunas y reducir riesgos de desastres (Betsill, 2001; Carmin, Anguelovski y Roberts, 2012; Etkin, Medalye y Higuchi, 2012; Heltberg, Siegel y Jorgensen, 2009; IPCC, 2012, p. 25-65; Carey et al., 2012, p. 736-737). Usamos la expresión GMRRD como abreviación de esas respuestas municipales.

La pregunta que motiva este análisis es por qué algunas municipalidades gestionan mejor el medioambiente, tienen mayor preparación para reducir riesgos de desastres, y aportan más a las capacidades de adaptación en la comuna.

En las últimas tres décadas, una creciente literatura ha subrayado la importancia de los factores políticos, los contextos institucionales y sociales para explicar diferencias de la GMRRD en la escala local (por ejemplo, Adger, 2003; Betsill, 2001; Burch, 2010; Carmin, Anguelovski y Roberts, 2012; Ostrom, 1990; Valdivieso y Andersson, 2017). Tomando en consideración esa literatura, este estudio explora la validez de las siguientes proposiciones. Primero, las respuestas de los municipios frente a los riesgos medioambientales se explican por los contextos comunales, factores contextuales e históricos. Segundo, si en contextos similares se observan diferencias en las respuestas de los gobiernos locales, las iniciativas de inversión, los presupuestos y las acciones municipales, entonces existen factores adicionales que explican las decisiones de los gobiernos locales. Tercero, en esas decisiones y acciones influyen factores políticos, arreglos y capacidades institucionales operando como barreras o facilitadores para la 
GMRRD municipal. Cuarto, la participación social y la interacción entre las organizaciones sociales y los gobiernos locales influyen en la gestión de riesgos medioambientales y tienen el potencial de enriquecer la gobernanza medioambiental de la comuna.

Chile es un caso apropiado para examinar empíricamente esas proposiciones. El territorio y la población nacional están expuestos y son vulnerables a riesgos medioambientales, y existen políticas nacionales proactivas de gestión medioambiental y reducción de riesgos (Valdivieso y Fonseca, 2015; Valdivieso, Andersson y Villena-Roldán, 2017). Por otra parte, las recurrentes situaciones de emergencia y desastres naturales que afectan a las comunas chilenas dejan en evidencia que los municipios difieren en su grado de preparación: algunos invierten, tienen planes y programas para GMRRD y están preparados, otros no.

Esta investigación usa métodos cualitativos y cuantitativos para examinar la validez de las proposiciones en el contexto empírico chileno. Dos municipios fueron identificados para un análisis cualitativo por compartir características de vulnerabilidad y riesgo con un conjunto mayor y por diferir en su GMRRD. El análisis incluyó inversiones, presupuestos y acciones de protección medioambiental y reducción de riesgos en el período 2009-2014 como variables manifiestas del concepto GMRRD. Con el propósito de explicar las diferencias observadas en los dos municipios, el análisis consideró las trayectorias institucionales, las preferencias de los políticos locales y los resultados electorales, los reglamentos municipales y las rutinas de los concejos municipales, las capacidades financieras y humanas y las interacciones de los gobiernos locales con la sociedad. El análisis cuantitativo examinó las proposiciones mediante la operacionalización de conceptos en variables manifiestas en 320 municipalidades y el diseño de modelos de regresión. Los procedimientos para documentar los casos y hacer el análisis cuantitativo consistieron en la búsqueda, selección y trabajo con fuentes primarias de información, la aplicación de entrevistas a jefes de hogar, dirigentes sociales y funcionarios municipales, la aplicación de encuestas a muestras representativas de población, y la búsqueda y recopilación de estadísticas en distintas fuentes nacionales, regionales y municipales.

Los resultados arrojan evidencias en apoyo de las proposiciones. El análisis contextualizado de los dos casos y los coeficientes de las regresiones sugieren que la combinación de los factores políticos, los arreglos y las capacidades institucionales de los dos municipios y las interacciones con la sociedad explican diferencias en la GMRRD. El análisis pone de manifiesto que no se trata de un solo factor institucional, sino de una combinación de factores que explican los comportamientos municipales y sus diferentes resultados en términos de GMRRD. En otras palabras, comparando comunas que tienen contextos similares y son afectadas por riesgos medioambientales, la probabilidad de una mejor gestión medioambiental es mayor en aquellos municipios que funcionan con concejos municipales independientes y responsables, organizaciones municipales flexibles, capacidades institucionales, y un sistema de gobernanza participativa. 


\section{Factores políticos, instituciones, sociedad, y gestión medioambiental y de reducción de riesgos}

Comparando la gestión medioambiental y acciones de reducción de riesgos de desastres en las municipalidades, la literatura contiene numerosas aproximaciones sobre opciones de la GMRRD (Pelling y High, 2005, p. 308; IPCC, 2012, p. 291-436; Dupuis y Biesbroeck, 2013, p. 1477-1478). Dupuis y Biesbroeck (2013, p. 1480-1481) recomiendan incluir en el análisis medidas que sean similares desde la perspectiva de los propósitos y sus resultados. Por lo tanto, nuestro estudio comparará iniciativas de inversión en proyectos de gestión medioambiental, fondos presupuestarios para las emergencias, y acciones similares de GMRRD. En los municipios chilenos esas medidas tienen el propósito de reducir la exposición y la vulnerabilidad ante los riesgos medioambientales y de desastres naturales.

Para entender mejor por qué algunas municipalidades tienen comportamientos proactivos y un mejor desempeño en términos de GMRRD, una parte de la literatura ha destacado la importancia de factores de naturaleza política que afectan los comportamientos municipales, por ejemplo, los intereses y las relaciones de poder (Waters, Barnett y Puleston, 2014, p. 691-693; Burch, 2010, p. 292-294). La literatura de la democracia de consenso y la descentralización (por ejemplo, Andersson y Van Laerhoven, 2007; Aklin et al, 2013; Freitag, 2006; Pasquini y Shearing, 2014) propone relaciones entre incentivos políticos y decisiones. Los alcaldes con base electoral y posiciones fuertes en el gobierno municipal, pero sin motivación por asuntos medioambientales, no destinan esfuerzos ni recursos para la GMRRD. Si los gastos e inversiones en GMRRD no tienen visibilidad ni importancia para los electores ni influyen en el acceso a nuevos recursos, los alcaldes y concejos municipales carecen de incentivos para la GMRRD.

Con sus normas internas, preferencias e ideologías, los agentes tienen la posibilidad de influir en las trayectorias municipales (Carmin, Anguelovski y Roberts, 2012; Sabatier et al., 1993; Maguire, Hardy y Lawrence, 2004, p. 657; Adger et al., 2009; Cashmore y Wejs, 2014; Holgate, 2007; Anguelovski y Carmin, 2011; Ingold y Fischer, 2014). Diversos estudios de casos han documentado los efectos positivos de los liderazgos políticos en la gestión medioambiental, por ejemplo, en procesos de cambio institucional y la institucionalización de objetivos medioambientales, las redes de gobernanza local y las relaciones de gobernanza multinivel (por ejemplo, Carmin, Anguelovski y Roberts, 2012; Cashmore y Wejs, 2014, p. 25-206; Anguelovski y Carmin, 2011, p. 173).

Otra parte de la literatura con un enfoque neo-institucionalista destaca la importancia de los arreglos y las estructuras institucionales. Las instituciones consisten en arreglos institucionales, normas y estructuras con la capacidad de influir en los comportamientos humanos y facilitar u obstaculizar las acciones colectivas (Ostrom, 1990, p. 1-28; Woolcock y Narayan, 2000, p. 11; Ahn y Ostrom, 2008, p. 73-74, 84). Las normas 
que operan como fuente de legitimidad, las trayectorias y lógicas inerciales pueden favorecer el statu quo, la resistencia al cambio institucional, dificultando la GMRRD en la escala local (Elmore, 1978; Maguire, Hardy y Lawrence, 2004, p. 658-659). La literatura ha identificado condiciones institucionales específicas que influyen en el comportamiento municipal, tales como reglamentos, procedimientos, fragmentación de departamentos, dificultad en la comunicación interna y legados y procedimientos de políticas previas (Holgate, 2007, p. 401; Burch, 2010, p. 15, 19; Anguelovski y Carmin, 2011; Larsen, Kørnøv y Wejs, 2012, p. 39; Harries y Penning-Rowsell, 2011, p. 190-191). Por otra parte, la literatura ha descrito también factores que facilitan la gestión medioambiental, por ejemplo, departamentos especializados en GMRRD, la planificación, comités interdepartamentales y reglas operacionales que promueven la independencia, la responsabilidad y la transparencia en los gobiernos locales (Agrawal y Ribot, 1999; Burch, 2010, p. 294-295; Harries y Penning-Rowsell, 2011, p. 195-197; Anguelovski y Carmin, 2011, p. 170).

Por su parte, la literatura de la adaptación en las ciudades ha subrayado la importancia de las capacidades institucionales para la GMRRD municipal, en particular los recursos financieros, humanos y el conocimiento técnico (Betsill, 2001, p. 399; Carmin, Anguelovski y Roberts, 2012, p. 20, 21-22; Satterthwaite, 2008, p. 44).

La literatura del Capital Social (CS) explica también variaciones en la GMRRD. En esa literatura, las relaciones sociales reiteradas, la confianza, la reciprocidad y los arreglos institucionales (en la sociedad y en las instituciones locales) tienen el potencial de influir en la GMRRD (Adger, 2003; Pelling y High, 2005; Norris et al., 2008; Dynes, 2002; Wolf et al., 2010; Jones, 2013; Gebremedhin, Pender y Tesfay, 2003; Keogh et al., 2011). Diversos estudios han documentado efectos de la participación social y CS en la gobernanza medioambiental y la reducción de riesgos de desastres (por ejemplo, Andersson y Van Laerhoven, 2007; Portney y Berry, 2014; Chen, Wang y Huang, 2014).

El CS bonding, formas de organización social cohesionadas, encapsuladas, con vínculos fuertes hacia su interior e intereses expresivos (Lin, 2008), podría tener efectos en la gestión medioambiental y la reducción de desastres. Adger (2003) plantea la posibilidad de que opere de forma positiva en contextos donde las instituciones son débiles y no tienen la capacidad de inclusión social en las políticas locales. Woolcock y Narayan (2000, p. 9-10) describen el CS bridging como formas de organización social con vínculos débiles que conectan hacia el exterior y se relacionan con las instituciones. Adger (2003, p. 394-395) argumenta que el CS bridging tiene efectos positivos en la gestión ambiental cuando se combina con instituciones abiertas, transparentes e inclusivas. Analizando esas formas de capital social y las instituciones, la literatura del CS linking destaca la importancia de las relaciones sinérgicas entre la sociedad, los contextos institucionales locales, y la capacidad de agencia de los líderes para la GMRRD (Aldrich, 2011; Rubin, 2015; Szreter y Woolcock, 2004; Vervisch y Titeca, 2010). 
La noción que los factores políticos, los arreglos y las capacidades institucionales y el CS influyen en la GMRRD municipal informa las expectativas teóricas y las hipótesis que serán examinadas en un contexto empírico en este estudio.

\section{Teoría e hipótesis}

La GMRRD es el resultado de decisiones que toman quienes participan en los gobiernos locales, en situaciones estructuradas, donde hay reglas de operación, rutinas, prioridades de la política municipal, y otros factores que tienen efectos en sus incentivos y preferencias. Los gobiernos locales invierten en iniciativas y acciones de gestión medioambiental, la mitigación y la preparación, tomando en consideración la información disponible que tienen sobre el contexto, sus interacciones, y la oportunidad de los recursos disponibles.

Cada gobierno local funciona con un set particular de características contextuales comunales y municipales $X$ que se manifiestan por medio de expectativas de costos heterogéneos y beneficios derivados de las decisiones colectivas sobre inversiones en gestión de riesgos medioambientales, la mitigación y el gasto de preparación para las emergencias. Por ejemplo, la vulnerabilidad dada por la localización geográfica, las características de la población comunal o la experiencia de eventos extremos influyen en la expectativa de costos y beneficios. Pero adicionalmente, la trayectoria institucional, las ideologías y los factores políticos, las posiciones de los alcaldes y de los concejales, los arreglos institucionales que se manifiestan, por ejemplo, en reglas de operación y la organización interna municipal, y las capacidades institucionales (recursos financieros, humanos y conocimiento técnico), influyen en la expectativa de costos y beneficios, en los incentivos, y en las decisiones. A su turno, la participación social en la comuna y las relaciones sinérgicas de las organizaciones sociales con el gobierno local aportan información y tienen el potencial de influir en las decisiones municipales.

Podemos representar los beneficios esperados de la inversión en gestión de riesgos medioambientales con una función creciente, continua y cóncava, y los costos por medio de una función convexa (Figura 1): 
Figura 1

Determinación de inversión óptima en GMRRD

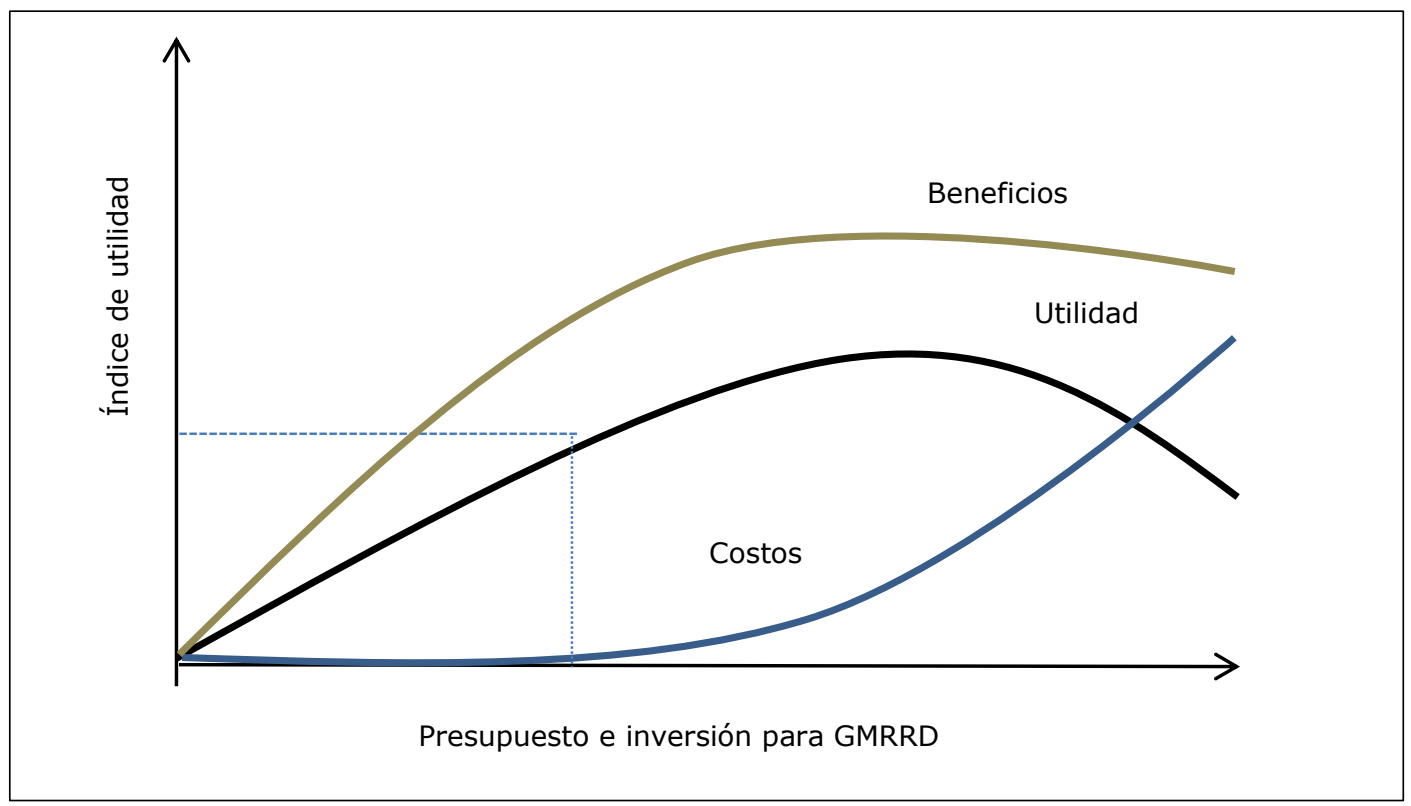

Fuente: Elaboración propia.

Bajo estos supuestos derivamos un nivel óptimo finito de inversión $Y_{i}$ del municipio $i$ que puede ser expresado en términos de un índice linear de características del vector $X_{i}$ tal como:

$$
Y_{i t}=\sum_{k=1}^{K} \alpha_{k} X_{k i}+\varepsilon_{i}=X_{i} \alpha+\varepsilon_{i}
$$

Donde $Y_{i t}$ representa la decisión del municipio $i$ en el tiempo $t, X$ los parámetros asociados con los factores que explican la decisión del municipio $i$, y $\varepsilon_{i}$ los errores aleatorios o factores estocásticos.

A partir de esta aproximación, examinaremos las siguientes hipótesis con el apoyo del análisis cualitativo y cuantitativo en municipios chilenos: (1) En contextos comunales afectados por riesgos medioambientales y de desastres naturales, los factores políticos (ideologías, resultados electorales y liderazgos) tienen efectos en las decisiones de los gobiernos locales, y por lo tanto también en la GMRRD; (2) Los arreglos institucionales que facilitan las decisiones informadas, la circulación de información y la coordinación interdepartamental dentro de los municipios aumentan la probabilidad de decisiones favorables para GMRRD; (3) Las capacidades institucionales, en particular los recursos financieros y humanos, explican comportamientos diferenciados en la GMRRD; (4) Las interacciones entre los gobiernos locales y la sociedad tienen efectos también en GMRRD, 
porque ponen en circulación información, influyen en expectativas y en los incentivos de los políticos locales.

\section{Procedimientos}

\section{Municipalidades y casos}

El territorio chileno está dividido en 346 comunas con municipalidades. El gobierno municipal está compuesto por el Alcalde y el Concejo Municipal (6 a 8 miembros), elegidos por votación popular cada cuatro años. El Concejo sesiona cuatro veces por mes y es responsable por decisiones para el desarrollo territorial, económico, social y medioambiental de la comuna. El Concejo toma decisiones sobre los presupuestos municipales, las inversiones, el personal, y los planes, programas y actividades. Además, cada municipalidad tiene departamentos para colaborar con las tareas municipales.

Para el análisis de este estudio, seleccionamos dos casos de comunas chilenas representativos de un número mayor, desde la perspectiva de la localización geográfica, condiciones de vulnerabilidad, y diferentes comportamientos en GMRRD. Con el apoyo de criterios de selección (riesgos medioambientales, vulnerabilidad), identificamos a Cauquenes (VII Región del Maule) y Panguipulli (IX Región de los Ríos) (Figura 2). Esas dos comunas están ubicadas en la depresión intermedia y la cordillera, son afectadas por problemas medioambientales y riesgos de desastres, y difieren en sus comportamientos. Comparando, Panguipulli se destaca por sus gastos, inversiones y acciones en GMRRD. 
Figura 2

Comunas seleccionadas

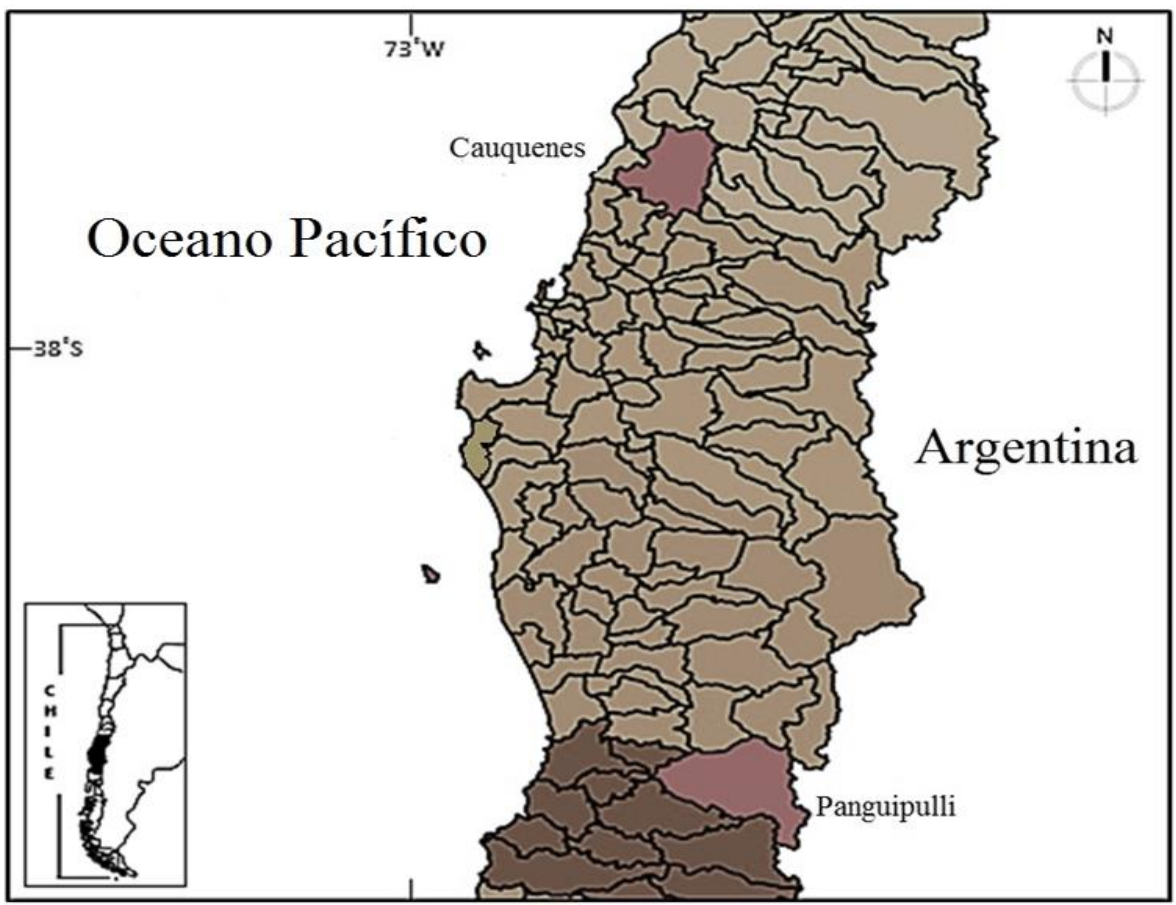

Fuente: Elaboración propia con base en Marín y Valdivieso (2016)

El análisis cuantitativo incluye una muestra de 320 municipios chilenos que comparten características similares: vulnerabilidad medioambiental y experiencias con eventos extremos, diferencias en la GMRRD.

\section{Análisis cualitativo}

Este estudio cubre el período 2009-2014 por la disponibilidad de registros para la investigación. El análisis contextualizado y comparado de los dos casos seleccionados fue realizado con el apoyo de análisis de contenido y la triangulación de información obtenida en diversas fuentes primarias (Cuadro A1 del Apéndice). La información fue ordenada y analizada para documentar los contextos comunales, las decisiones presupuestarias, de inversión, y las acciones municipales en GMRRD, las rutinas y decisiones de los gobiernos 
locales (concejos municipales), los factores políticos y las trayectorias institucionales, las reglas de operación y la organización interna, y las relaciones con la sociedad.

\section{Análisis cuantitativo}

La información cuantitativa fue ingresada en una base de datos que contiene registros sobre 320 municipios que tomaron decisiones de inversiones en gestión medioambiental, mitigación presupuestos de emergencia, y acciones en GMRRD entre los años 2009 y 2014.

El análisis consideró las siguientes variables dependientes: (1) Costos de proyectos en gestión medioambiental; (2) Costos de proyectos en mitigación; (3) Fondos presupuestarios de emergencia. Los proyectos de gestión medioambiental son iniciativas para mejorar las condiciones medioambientales de la comuna y reducir riesgos, por ejemplo, energías renovables o protección de bosques. Las iniciativas de mitigación deben reducir o revertir daños medioambientales que exponen a riesgos, tales como intervenciones humanas que causan contaminación. Con la orientación de diversas tipologías consultadas en la literatura (IPCC, 2012), procedimos a seleccionar información sobre los costos de los proyectos de gestión medioambiental y mitigación ingresados a la base integrada de proyectos de inversión del Ministerio de Desarrollo Social para los años 2009, 2010, 2011, 2012, 2013 y 2014. Los fondos de emergencia representan las capacidades de los municipios para prepararse y enfrentar problemas causados por eventos extremos en la comuna y responder cuando se desencadenan los eventos y en la fase de recuperación. Las fuentes primarias consultadas fueron los presupuestos municipales anuales destinados a fondos de emergencia para los años 2009-2014. La variable fue calculada como el porcentaje de esos fondos de emergencia en el presupuesto anual del municipio.

Las variables independientes corresponden a cuatro categorías: (1) Factores Políticos; (2) Arreglos Institucionales; (3) Capacidades Institucionales; y (4) Variables Sociales. La primera variable de Factores Políticos es el "Índice Herfindahl" de concentración de votos del alcalde con información electoral (2004, 2008 y 2012) disponible en el Servicio Electoral de Chile (Servel, 2012), con la expectativa que el posicionamiento electoral del alcalde tiene efectos en la GMRRD. La variable "Afiliación" del alcalde (centro izquierdo, centro derecha) fue incluida con la expectativa que la ideología y la afiliación partidista afecta la GMRRD.

En la segunda categoría Arreglos Institucionales, la variable "Independencia del Concejo" consiste en un índice diseñado con información reglamentaria que informa sobre el grado de independencia del concejo municipal con respecto al alcalde para tomar decisiones. El índice fue construido con información reglamentaria referida a facultades y atribuciones del concejo, por ejemplo, si los concejales tienen autonomía para formar comisiones de estudio. La variable "Flexibilidad Organizacional" es un índice que ordena 
municipios según atributos tales como el grado de coordinación interna con información reglamentaria.

Incluyendo capacidades institucionales, la variable "Fondo Común Municipal" (porcentaje en el ingreso municipal) informa sobre la dependencia del presupuesto municipal de transferencias externas, con la expectativa que a mayor dependencia menores capacidades financieras para GMRRD. El "Gasto en Personal" (porcentaje del gasto total) compite con otros ítems presupuestarios, por lo tanto, a mayor magnitud de ese gasto mayores restricciones para gastos en GMRRD. Inversamente, la variable "Profesionales GMRRD" (porcentaje de funcionarios de medioambiente y emergencias en el total de profesionales) manifiesta capacidades humanas para la GMRRD.

En la cuarta categoría CS, la variable "Participación Social" (porcentaje) fue construida con información de las encuestas nacionales de caracterización socioeconómica Casen (años 2009, 2011 y 2013, disponibles en el Ministerio de Desarrollo Social, 2014). La variable "Densidad de Organizaciones" consiste en tasas de organizaciones sociales por cada 1000 habitantes, con registros del servicio nacional de información municipal y las bases de datos del Servicio de Registro Civil e Identificación.

Para controlar efectos de las variables independientes, el diseño incluyó las siguientes medidas: (1) "Costos de Eventos Pasados" (climáticos y geofísicos) 1971-2011 disponibles en Desinventar (2014); (2) "Eventos Registrados" 2008-2014 (con base de datos facilitada por el Ministerio de Agricultura de Chile); (3) "Índice de Ruralidad" o dependencia de los recursos naturales; (4) "Pobreza" (porcentaje) con información de la encuesta Casen; (5) "Superficie"; (6) "Población"; (7) "Emplazamiento" (depresión intermedia y zona cordillerana).

El panel de datos de inversiones y gastos de 320 municipios entre los años 2009 y 2014 posibilita controlar las relaciones postuladas en las hipótesis por la heterogeneidad no observada. El análisis considera la estimación de las siguientes ecuaciones:

(2) $Y_{i t}=X_{i t} \alpha+\varepsilon_{i t}$

(3) $Y_{i t}=X_{i t} \alpha+v_{i}+\varepsilon_{i t}$

La especificación (2) es una regresión lineal OLS (mínimos cuadrados ordinarios) que no controla por la heterogeneidad no observada, es decir factores específicos de cada comuna. El efecto es estimado solamente como un término de error aleatorio que no está correlacionado con las variables explicativas del modelo. La especificación (3) con efectos variables controla por los efectos de la heterogeneidad no observada. 


\section{Fuentes de información}

La información fue recopilada entre los años 2013 y 2016. Primero, trabajo con la literatura disponible, búsqueda de documentación, aplicación de entrevistas a funcionarios municipales, jefes de hogar y dirigentes sociales (Cuadro A2 del Apéndice). Segundo, aplicación de encuestas a muestras representativas de jefes de hogar en las dos comunas (casos: Cauquenes 200; Panguipulli 210), y la revisión de registros y fuentes oficiales (2009-2014).

La información para el análisis cuantitativo fue recolectada y procesada durante los años 2014-2016. La recopilación y la solicitud de registros con información por teléfono, internet y mediante cuestionarios, permitió reunir información para las estimaciones.

\section{Resultados}

El análisis de los resultados sugiere que los factores políticos, los arreglos y las capacidades institucionales, y las relaciones entre los municipios y la sociedad explican comportamientos municipales y GMRRD. El análisis ha sido estructurado en dos partes: (1) Contextos, políticas nacionales y comportamientos municipales; (2) Examen de las hipótesis.

\section{Contextos, políticas nacionales y comportamientos municipales}

\section{Exposición, vulnerabilidad y riesgos}

La localización de Chile en el círculo de fuego del Pacífico, entre las coordenadas $17^{\circ}-56^{\circ} \mathrm{S}$ y $66^{\circ}-75^{\circ} \mathrm{W}$, expone a frecuentes terremotos, tsunamis, y erupciones volcánicas. El territorio chileno está siendo afectado por los fenómenos El Niño y La Niña, y por el cambio climático (World Bank, 2009; Valdivieso, Andersson y Villena-Roldán, 2017). Las comunas chilenas han tenido experiencias con eventos extremos que han causado pérdidas humanas y materiales (Desinventar, 2014).

Los entrevistados y una parte de los jefes de hogar encuestados en Cauquenes y Panguipulli relacionaron el concepto riesgo medioambiental con experiencias, efectos en sus condiciones de vida, y su preocupación por la posibilidad de desastres (Cuadro A3 en Apéndice). Los registros disponibles indican que esas comunas están expuestas a riesgos medioambientales, enfrentan periódicamente situaciones de emergencia por sequías e incendios forestales, inundaciones, nevazones y heladas (Cuadro A4 en Apéndice). La sobreexplotación de recursos naturales y la contaminación han dañado el medio ambiente (suelos erosionados, aguas, aire, pérdida de biodiversidad), aumentando la exposición y el riesgo (Valdivieso y Andersson, 2017). 
Un significativo porcentaje de la población es vulnerable frente a los riesgos medioambientales por sus condiciones habitacionales, deficiente infraestructura sanitaria, el aislamiento, el desempleo crónico, bajos ingresos y la pobreza (Cuadro A5 en Apéndice). En las zonas urbanas, una parte de los jefes de hogar relacionó el mal estado de las viviendas y de la infraestructura vial con el concepto de exposición, y en las zonas rurales las dificultades de acceso a recursos hídricos, la falta de servicios sanitarios, el deficiente estado de los caminos, la inestabilidad laboral, carencia de servicios de salud y el aislamiento.

\section{Políticas nacionales}

En Chile existen políticas nacionales de gestión medioambiental y reducción de riesgos (Valdivieso y Andersson, 2017), y los gobiernos municipales cuentan con facultades y atribuciones para preparar a sus comunas y responder al desafío. Paradójicamente, las recurrentes situaciones de emergencia y desastres naturales dejan en evidencia que los municipios difieren en su grado de preparación: algunos han invertido, tienen planes, programas, ejecutan acciones para GMRRD y están preparados, otros no.

Durante las últimas tres décadas, los gobiernos han adoptado políticas para GMRRD: estrategia multisectorial de adaptación al Cambio Climático (2008-2012; 20132017); plan nacional de adaptación en el sector agrícola (World Bank, 2009); instituciones para la protección medioambiental, tales como el Sistema de Evaluación de Impacto Medioambiental, la Superintendencia y los ministerios del Medio Ambiente y de Energía (2010).

Para la prevención y la protección ante eventos sísmicos existen normas de construcción y urbanismo, planes de ordenamiento territorial y estándares de reducción de desastres (Santa María et al., 2010). El Sistema Nacional de Protección Civil (1974) contiene procedimientos para la prevención y reducción de desastres. El Plan Nacional (Decreto no 156, 2002) entrega la coordinación a la Oficina Nacional de Emergencias del Ministerio del Interior (Onemi), involucrando los niveles nacional, regional, provincial y municipal, con procedimientos de coordinación. El Plan incluye actividades de prevención, mitigación, preparación, respuesta, recuperación y reconstrucción. Empero, los estudios disponibles informan sobre diferentes comportamientos municipales en GMRRD (por ejemplo, Sánchez, 2010; Valdivieso, Andersson y Villena-Roldán, 2017).

\section{Comportamientos municipales}

En las comunas de Cauquenes y Panguipulli, los funcionarios entrevistados relacionaron el concepto GMRRD con presupuestos, inversiones, ordenanzas, planes, acciones y programas decididos por los concejos. El año 2014, el Concejo Municipal de Panguipulli destinó mayor cantidad de sesiones y de tiempo para el tratamiento de 
problemas e iniciativas relacionadas con la gestión de riesgos medioambientales y la mitigación.

Las ordenanzas municipales contienen mandatos, autorizaciones y prohibiciones sobre asuntos específicos bajo la jurisdicción municipal. De 40 ordenanzas legisladas por el Concejo Municipal de Panguipulli en el período 2008-2014, el 22\% incluyó regulaciones de protección medioambiental y reducción de riesgos ${ }^{1}$. En el caso de Cauquenes, sólo dos de un total de $15(13 \%)^{2}$.

La Figura 3 muestra que Panguipulli invirtió más que Cauquenes en GMRRD, en estudios, planes de descontaminación y minimización de riesgos sanitarios, reciclaje y composta, fiscalización de actividades contaminantes y monitoreo de indicadores de sustentabilidad. Para reducir riesgos, financió infraestructura para los bomberos, planes de contingencia, y viviendas sociales de emergencia. Cauquenes invirtió mínimamente en el servicio de bomberos.

\footnotetext{
1 Medio Ambiente - 2007; Turismo Aventura - 2008; Servicios Turísticos - 2008; Plan Ordenamiento Turístico Siete Lagos - 2008; Corredores Turísticos - 2010; Red Humedales - 2010; Pesca - 2010; Ordenanza local para apicultores - 2014; Uso y entrega de bolsas de polietileno y papel - 2014.

2 Construcción de Áreas Verdes y Arborización de Calles de Cauquenes - 2007; Ordenanza Local Plan Regulador de Cauquenes - 2009.
} 
Figura 3

Inversiones y presupuestos

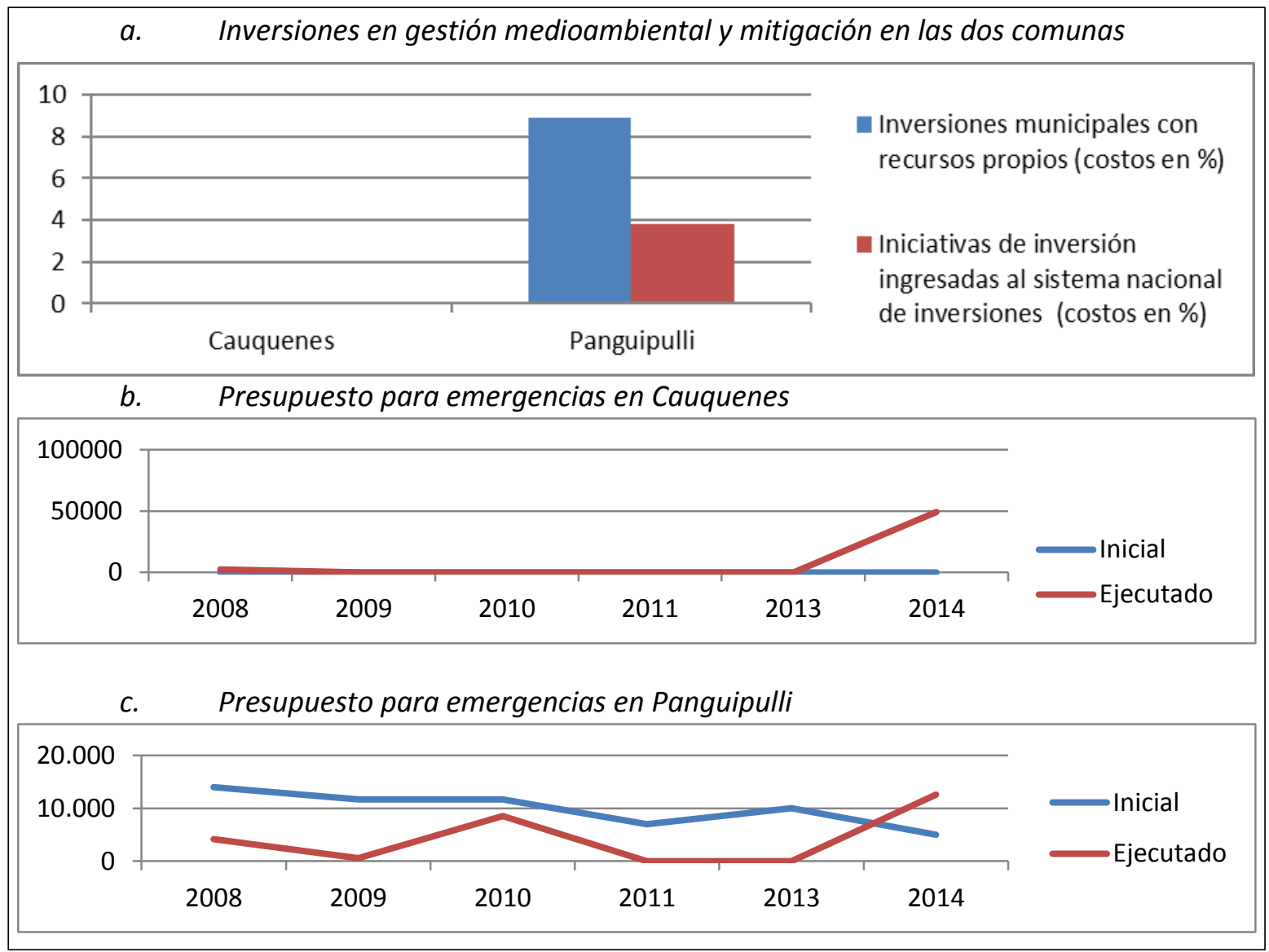

Fuente: Presupuestos municipales iniciales facilitados por secretarias municipales; Sinim (2014); Ministerio de Desarrollo Social (2014), "Banco integrado de proyectos", disponible en:

<https://bip.ministeriodesarrollosocial.gob.cl/bip2trabajo/app/login;jsessionid=BD56E675D39791926463F1A16 D805578>, acceso en: 23 nov. 2017.

Nota: Las columnas de la figura a representan porcentajes de los costos totales tanto de inversión municipal directa como de la inversión realizada por medio de proyectos ingresados en el Sistema Nacional de Inversiones.

Los municipios usaron fondos presupuestarios para prevenir y mitigar en situaciones de emergencia en el período 2009-2014. Panguipulli estuvo mejor preparado para enfrentar situaciones de emergencia en cinco años, mientras que Cauquenes debió reasignar recursos presupuestarios para hacer frente a situaciones, para las cuales no tenía preparación, durante tres años.

Al ser consultados por 19 actividades deseables de protección medioambiental, el funcionario responsable de medioambiente en Panguipulli informó que el municipio realiza $16(84 \%)$, mientras que funcionario encargado de Medioambiente de Cauquenes informó sobre 2 (10\%) (Cuadro A5). Consultados los funcionarios de medioambiente por 20 
actividades y acciones de prevención y reducción de riesgos, el de Panguipulli informó 14 actividades (70\%), el de Cauquenes sólo 9 (45\%) (Cuadro A6).

Particularmente relevantes son las intervenciones de los municipios en el Sistema de Evaluación de Impacto Medioambiental (SEIA), donde son evaluados proyectos de inversión. Comparando en el período 2007-2014, Panguipulli elaboró informes sobre 28 iniciativas de inversión (93\% del total), con observaciones sobre disposiciones de las ordenanzas medioambientales (21), riesgos medioambientales (13), y de desastres (12). En el mismo período, Cauquenes elaboró sólo 3 informes ( $37 \%$ del total) con observaciones de riesgos.

En suma, Panguipulli destacó por la tematización de los asuntos medioambientales y de riesgos en el Concejo Municipal, la legislación de ordenanzas, por sus iniciativas de inversión, presupuestos, acciones e intervenciones en la GMRRD. Cauquenes, en cambio, representa una gran cantidad de municipios chilenos que no priorizan GMRRD.

\section{Examen de las hipótesis}

Los resultados del análisis cualitativo y cuantitativo están ordenados en relación con las hipótesis sobre factores políticos, arreglos institucionales y sociales en la explicación de los comportamientos municipales.

Los Cuadros 1, 2 y 3 contienen los resultados de las regresiones, los coeficientes de regresión con los errores estándar robustos entre paréntesis. Con el propósito de interpretar los coeficientes como unidades de elasticidad, éstos fueron transformados en logaritmos. Por ejemplo, en el caso de la superficie, la lectura de los coeficientes informa sobre el cambio que produce cada incremento de $1 \%$ de superficie comunal en el presupuesto de emergencia, y el cambio se lee en "unidades logarítmicas" (UL). 


\section{Cuadro 1 \\ Inversiones en gestión medioambiental}

\begin{tabular}{|c|c|c|}
\hline \multicolumn{3}{|c|}{ Modelo 1: Inversiones en gestión medioambiental (VD) } \\
\hline & OLS Agrupada & Efectos aleatorios \\
\hline \multicolumn{3}{|l|}{ Factores Políticos } \\
\hline Índice Herfindahl & $-1,052(1,106)$ & $-0,732(1,196)$ \\
\hline Afiliación Centro-izquierda & $-0,143(0,253)$ & $-0,387(0,294)$ \\
\hline Afiliación Centro-derecha & $-0,560(0,272) * *$ & $-0,755(0,325) * *$ \\
\hline \multicolumn{3}{|l|}{ Arreglos Institucionales } \\
\hline Independencia del Concejo & $1,352(0,453) * * *$ & $1,355(0,658) * *$ \\
\hline Flexibilidad Organizacional & $1,806(0,796) * *$ & $1,751(1,114)$ \\
\hline \multicolumn{3}{|l|}{ Capacidades institucionales } \\
\hline Fondo Común Municipal & $-0,00822(0,00536)$ & $-0,0142(0,00617) * *$ \\
\hline Gastos en Personal & $-0,569(6,691)$ & $6,377(9,159)$ \\
\hline Profesionales GMRRD & $13,51(8,107) *$ & $17,86(8,311) * *$ \\
\hline \multicolumn{3}{|l|}{ Sociales } \\
\hline Participación social & $-0,253(0,504)$ & $-0,302(0,740)$ \\
\hline Densidad de organizaciones & $0,0179(0,00732) * *$ & $0,0206(0,00985) * *$ \\
\hline \multicolumn{3}{|l|}{ Controles } \\
\hline Costos de Eventos Pasados & $0,0238(0,0291)$ & $0,0281(0,0356)$ \\
\hline Eventos Registrados & $-0,485(0,519)$ & $-0,400(0,667)$ \\
\hline Índice de Ruralidad & $-0,0402(0,0530)$ & $-0,0462(0,0636)$ \\
\hline Pobreza & $0,0439(0,0305)$ & $0,0325(0,0385)$ \\
\hline Superficie & $0,144(0,125)$ & $0,143(0,170)$ \\
\hline Población & $0,236(0,159)$ & $0,264(0,208)$ \\
\hline Emplazamiento: Depresión intermedia & $0,628(0,299) * *$ & $0,612(0,394)$ \\
\hline Emplazamiento: Cordillera & $0,535(0,345)$ & $0,452(0,450)$ \\
\hline Constante & $0,373(2,619)$ & $0,432(3,756)$ \\
\hline Observaciones & 1,499 & 1,499 \\
\hline R-cuadrada & 0,127 & \\
\hline Número de municipios & 319 & \\
\hline
\end{tabular}

Fuente: Elaboración propia con datos del Proyecto Fondecyt no 1140672 y programa STATA 10.0.

Nota: Errores estándares robustos entre paréntesis; $* * * \mathrm{p}<0,01, * * \mathrm{p}<0,05, * \mathrm{p}<0,1$. Controlados por variables dicotómicas anuales y regionales. 


\section{Cuadro 2 \\ Inversiones en mitigación}

\begin{tabular}{|c|c|c|}
\hline \multicolumn{3}{|c|}{ Modelo 2: Inversiones en mitigación (VD) } \\
\hline & OLS Agrupada & Efectos aleatorios \\
\hline \multicolumn{3}{|l|}{ Políticos } \\
\hline Índice Herfindahl & $-1,372(0,574) * *$ & $-1,348(0,666) * *$ \\
\hline Afiliación Centro-izquierda & $-0,174(0,125)$ & $-0,210(0,164)$ \\
\hline Afiliación Centro-derecha & $-0,136(0,133)$ & $-0,0671(0,181)$ \\
\hline \multicolumn{3}{|l|}{ Arreglos Institucionales } \\
\hline Independencia del Concejo & $0,0615(0,244)$ & $0,0552(0,367)$ \\
\hline Flexibilidad Organizacional & $0,476(0,479)$ & $0,418(0,622)$ \\
\hline \multicolumn{3}{|l|}{ Capacidades institucionales } \\
\hline Fondo Común Municipal & $-0,00701(0,00300) * *$ & $-0,0690(0,0344)^{* *}$ \\
\hline Gastos en Personal & $1,691(4,110)$ & $0,426(5,116)$ \\
\hline Profesionales GMRRD & $6,174(3,396) *$ & $-4,538(4,642)$ \\
\hline \multicolumn{3}{|l|}{ Sociales } \\
\hline Participación social & $-0,661(0,262) * *$ & $-0,670(0,413)$ \\
\hline Densidad de organizaciones & $0,0136 * * *(0,00467)$ & $0,0128 * *(0,00549)$ \\
\hline \multicolumn{3}{|l|}{ Controles } \\
\hline Costos de Eventos Pasados & $-0,00916(0,0174)$ & $-0,00670(0,0198)$ \\
\hline Eventos Registrados & $-0,493(0,202) * *$ & $-0,476(0,372)$ \\
\hline Índice de Ruralidad & $-0,0605(0,0263) * *$ & $-0,0560(0,0355)$ \\
\hline Pobreza & $0,0387(0,0119) * * *$ & $0,0392 *(0,0215)$ \\
\hline Superficie & $0,0844(0,0723)$ & $0,0736(0,0950)$ \\
\hline Población & $0,0222(0,0917)$ & $0,00194(0,116)$ \\
\hline Emplazamiento: Depresión intermedia & $0,0717(0,209)$ & $-0,0612(0,220)$ \\
\hline Emplazamiento: Cordillera & $-0,0730(0,222)$ & $0,0665(0,249)$ \\
\hline Constante & $2,933(1,186) * *$ & $3,119(2,095)$ \\
\hline Observaciones & 1,503 & 1,503 \\
\hline R-cuadrada & 0,108 & \\
\hline Número de municipios & & 320 \\
\hline
\end{tabular}

Fuente: Elaboración propia con datos del Proyecto Fondecyt no 1140672 y programa STATA 10.0.

Nota: Errores estándares robustos entre paréntesis; $* * * \mathrm{p}<0,01 * * \mathrm{p}<0,05, * \mathrm{p}<0,1$. Controlados por variables dicotómicas anuales y regionales. 


\section{Cuadro 3 \\ Presupuestos de emergencia}

\begin{tabular}{|c|c|c|}
\hline \multicolumn{3}{|c|}{ Modelo 3: Presupuestos de emergencia (VD) } \\
\hline & OLS Agrupada & Efectos aleatorios \\
\hline \multicolumn{3}{|l|}{ Políticos } \\
\hline Índice Herfindahl & $-0,590(0,731)$ & $-0,951(0,815)$ \\
\hline Afiliación Centro-izquierda & $0,228(0,174)$ & $0,0665(0,226)$ \\
\hline Afiliación Centro-derecha & $0,293(0,189)$ & $0,0659(0,251)$ \\
\hline \multicolumn{3}{|l|}{ Arreglos Institucionales } \\
\hline Independencia del Concejo & $1,156(0,318) * * *$ & $1,093(0,539) * *$ \\
\hline Flexibilidad Organizacional & $6,744(0,552) * * *$ & $6,835(0,912) * * *$ \\
\hline \multicolumn{3}{|l|}{ Capacidades institucionales } \\
\hline Fondo Común Municipal & $-0,00587(0,00398)$ & $-0,00215(0,00388)$ \\
\hline Gastos en Personal & $-0,736(4,519)$ & $-0,400(6,730)$ \\
\hline Profesionales GMRRD & $-0,518(5,337)$ & $1,512(5,661)$ \\
\hline \multicolumn{3}{|l|}{ Sociales } \\
\hline Participación social & $1,094(0,390) * * *$ & $1,133(0,605) *$ \\
\hline Densidad de organizaciones & $-0,00481(0,00461)$ & $-0,00380(0,00805)$ \\
\hline \multicolumn{3}{|l|}{ Controles } \\
\hline Costos de Eventos Pasados & $0,00576(0,0179)$ & $0,00327(0,0291)$ \\
\hline Eventos Registrados & $-0,729(0,334) * *$ & $-0,717(0,547)$ \\
\hline Índice de Ruralidad & $-0,0488(0,0360)$ & $-0,0403(0,0519)$ \\
\hline Pobreza & $0,0551(0,0188) * * *$ & $0,0536(0,0314) *$ \\
\hline Superficie & $-0,0617(0,0862)$ & $-0,0278(0,139)$ \\
\hline Población & $0,876(0,108) * * *$ & $0,905(0,170) * * *$ \\
\hline Emplazamiento: Depresión intermedia & $-0,0541(0,211)$ & $0,00578(0,323)$ \\
\hline Emplazamiento: Cordillera & $0,183(0,223)$ & $0,199(0,366)$ \\
\hline Constante & $-7,822(2,080) * * *$ & $-8,586(3,066) * * *$ \\
\hline Observaciones & 1,798 & 1,798 \\
\hline R-cuadrada & 0,499 & \\
\hline Número de municipios & & 320 \\
\hline
\end{tabular}

Fuente: Elaboración propia con datos del Proyecto Fondecyt $n^{0} 1140672$ y programa STATA 10.0.

Nota: Errores estándares robustos entre paréntesis; $* * * p<0,01, * * p<0,05, * p<0,1$. Controlados por variables dicotómicas anuales y regionales.

\section{Factores políticos}

La primera hipótesis propone que los liderazgos y trayectorias, ideologías, y resultados electorales tienen efecto en las decisiones de los gobiernos locales, y, por lo tanto, en la GMRRD. El análisis cualitativo de Cauquenes y Panguipulli arroja evidencia 
sobre la asociación entre las trayectorias institucionales, ideología de los alcaldes, resultados electorales y GMRRD.

Hasta el 2000, los dos municipios tenían características político-institucionales similares: agenda de control de los alcaldes, estructura municipal jerárquica y departamentos aislados, ejecución de políticas y programas nacionales, y distancia con la sociedad local. Los reglamentos internos combinados con comportamientos institucionales inerciales daban lugar a rutinas burocráticas que obstruían la innovación en las políticas locales (Valdivieso y Andersson, 2017). No obstante ser comunas afectadas por la degradación medioambiental y riesgos de desastres, los municipios no priorizaban la GMRRD.

A partir de 2000, la elección del alcalde Alejandro Kohler (2000-2008) dio lugar al cambio institucional en Panguipulli (Municipalidad de Panguipulli, 2008) 3 con la aprobación de nuevos reglamentos internos $(2004,2005)$, creación de un Departamento de Ordenamiento Territorial y Medio Ambiente en la Secretaría de Planificación Municipal, introducción de la informática en el quehacer municipal, contratación de 30 profesionales jóvenes en distintos departamentos, nuevos procedimientos para fortalecer la coordinación de los departamentos y los vínculos externos del municipio, y la introducción de la Agenda 21 Local (2005) en la planificación.

Tres factores motivaron el programa de Kohler: primero, la experiencia de vida en una comuna vulnerable con grandes desigualdades y exclusión social, y sus convicciones familiares y personales que le llevaron a militar en partidos de izquierda; segundo, la experiencia de exilio en Alemania durante el gobierno de la dictadura militar (1973-1985), donde estudió, trabajó y se familiarizó con las perspectivas, experiencias y políticas del desarrollo endógeno sustentable; tercero, una experiencia de micro-emprendimiento turístico exitosa y su visión del turismo sustentable en la comuna.

El cambio institucional iniciado en el período de Kohler fue reforzado posteriormente. Los distintos actores políticos de la comuna compartían la motivación por promover el turismo y el desarrollo sustentable, prácticas institucionales más participativas, rutinas de coordinación interdepartamental, fortalecimiento de vínculos con distintos actores externos, apertura y relaciones sinérgicas con las organizaciones sociales (Valdivieso, 2016).

En el período 2008-2014, las trayectorias y liderazgos de los alcaldes de ambos municipios explican distintos comportamientos en GMRRD. El alcalde de Cauquenes, afiliado al partido de centro-derecha Renovación Nacional, tenía trayectoria en el municipio y el gobierno regional y priorizó el crecimiento económico y la infraestructura productiva en su agenda (Municipalidad de Cauquenes, 2014; Muñoz, 2012). Los reglamentos internos favorecieron su control de la agenda municipal. La situación del alcalde de centro-derecha

\footnotetext{
${ }^{3}$ El ex Alcalde Kohler aceptó la invitación a participar en esta investigación como entrevistado, dando su consentimiento informado, y validó posteriormente las informaciones sintetizadas, autorizando que se le cite como fuente de información.
} 
de Panguipulli difería en dos aspectos: primero, el arreglo institucional municipal (reglamentos internos, organización municipal) facilitaba el balance de poder y relaciones competitivas en el Concejo Municipal, impidiendo su control de la agenda; segundo, el alcalde priorizaba la sustentabilidad medioambiental en la agenda municipal (Aravena, 2008). Contrastando con Cauquenes, la organización municipal de Panguipulli contaba con más capacidades financieras y humanas, y producía circulación de información sobre GMRRD. La combinación de prioridades del alcalde, el papel proactivo de los concejales, y la coordinación interna estaba correlacionada con más relaciones e interacciones entre el Concejo y actores de otros niveles de gobernanza de GMRRD (ministerios, gobierno regional, empresas, organizaciones sociales).

Los resultados electorales fortalecieron el liderazgo y la agenda del alcalde de Cauquenes. En las elecciones municipales (2008 y 2012), el mismo candidato a alcalde obtuvo amplia mayoría de votos ( $55 \%$ en promedio), al igual que los candidatos a concejales de su coalición. En Panguipulli, las elecciones eran competitivas; el año 2012, el candidato a alcalde obtuvo el $46 \%$ de los votos, y más de la mitad de los concejales electos no pertenecía a su coalición política. Esos resultados combinados con distintas prioridades y los arreglos institucionales municipales explican diferencias. Contrastando con la falta de voluntad política en Cauquenes por priorizar GMRRD, en Panguipulli había consenso en torno a la sustentabilidad, mayor equilibrio de poder y competencia política en el seno del gobierno municipal, y mayor circulación de información sobre las condiciones medioambientales y riesgos en la comuna.

Observando en una muestra mayor de municipios, los resultados del análisis cuantitativo son consistentes con los hallazgos del análisis cualitativo sobre efectos de los factores políticos en GMRRD. Las variables "Concentración de Votos del Alcalde" y la "Ideología" (centro-derecha) tienen efectos negativos en las inversiones en GMRRD. En el modelo 2 (Cuadro 2), el índice de concentración de votos del alcalde tiene coeficientes negativos de 1,372 y 1,348 (significancia al $p<0.05$ ). Una unidad de aumento en el índice de concentración de votos del alcalde induce un decrecimiento en las inversiones municipales en mitigación entre 1,372 y 1,348 unidades logarítmicas ( $u l)$. En el modelo 1 (Cuadro 2), la ideología del alcalde de centro-derecha tiene coeficientes negativos de 0,560 y 0,755 (significancia al $p<0.05$ ). Cuando el alcalde es de centro-derecha disminuyen las inversiones en protección medioambiental entre 0,560 y 0,560 ul. En Chile, la ideología de centro-derecha promueve los mercados y el crecimiento económico, mientras que la de centro-izquierda el estado de bienestar y el gasto público. 


\section{Arreglos institucionales}

La segunda hipótesis sostiene que arreglos institucionales que incentivan la independencia y la responsabilidad de los concejales, la circulación de información y la coordinación interdepartamental aumentan la probabilidad de mejor GMRRD.

El análisis cualitativo arroja evidencia en apoyo de la hipótesis. En Cauquenes, el Reglamento del Concejo Municipal otorgaba amplias facultades al alcalde para dirigir el municipio, las sesiones del Concejo y controlar los flujos de información (Figura 4). Por ejemplo, el alcalde tenía representación en las comisiones de estudio del Concejo, autorizaba el acceso a información de las oficinas municipales y las relaciones con actores externos; la ordenanza de participación ciudadanía disponía un mínimo de cien firmas para obtener una audiencia con el Concejo, y las audiencias no eran agendadas en sesiones ordinarias. Contrastando, el Reglamento de Panguipulli no contenía restricciones para las interacciones con actores externos, las que eran frecuentes, los concejales tenían la facultad de formar autónomamente comisiones de estudio, integrar en ellas a los funcionarios, solicitar los antecedentes que consideraban necesarios para su trabajo, fiscalizar y enviar informes al Concejo. 
Figura 4

\section{Esquema simplificado de la agenda de control del alcalde, caso de Cauquenes}

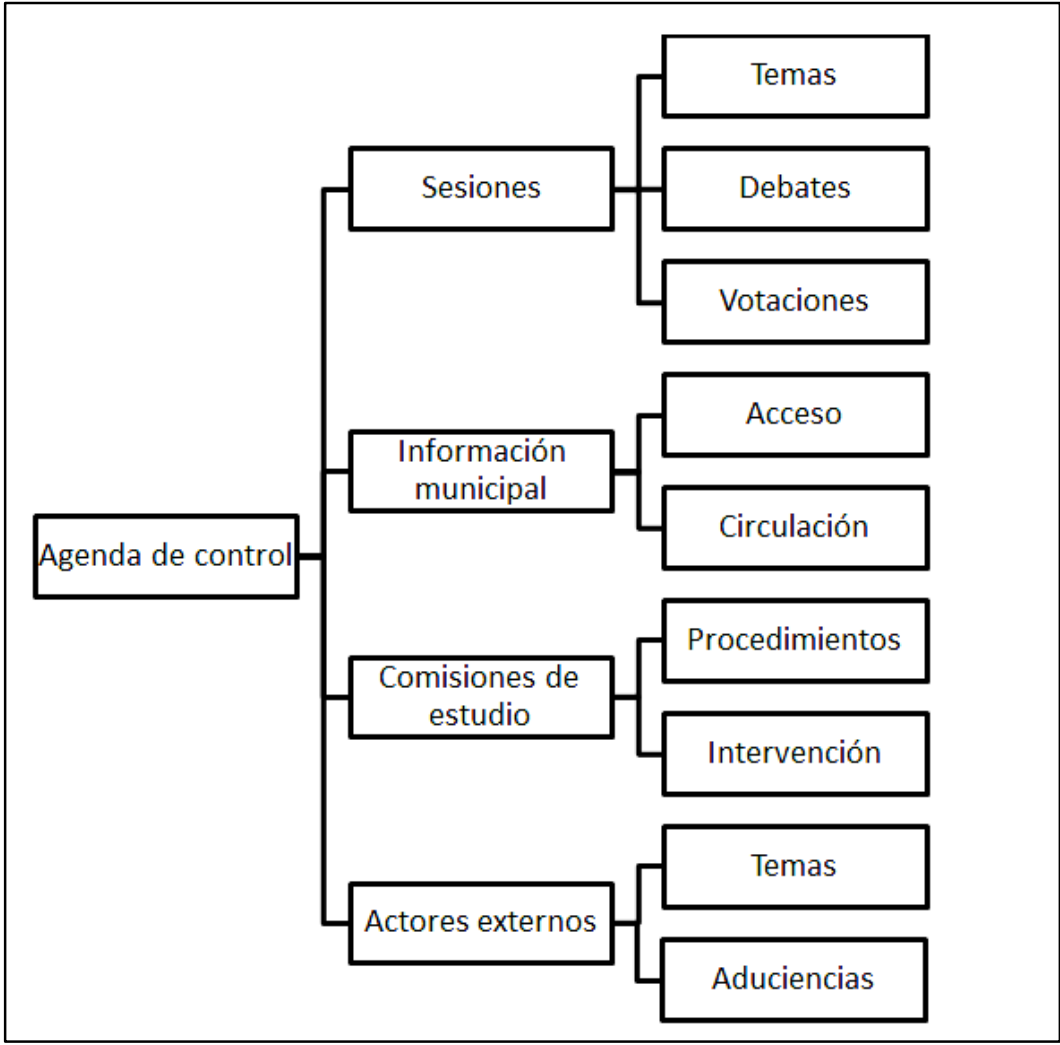

Fuente: Elaboración propia.

Las rutinas en las reuniones del Concejo Municipal de Cauquenes consistían en circulación de información relacionada con la agenda del alcalde, donde los asuntos de GMRRD no eran prioridad. Los concejales apoyaban las iniciativas del alcalde. En Panguipulli, el alcalde y los concejales priorizaban asuntos de GMRRD, examinaban propuestas, deliberaban, salían a terreno, ingresaban inquietudes ciudadanas en las discusiones, y mantenían relaciones más competitivas (cooperación y conflicto). Entre enero y diciembre del 2014, ingresaron a los concejos en promedio 125 asuntos relacionados con la gestión de riesgos, la mitigación y la reducción de la vulnerabilidad (Cauquenes 93, Panguipulli 157). En Cauquenes, los concejales intervinieron en diecisiete oportunidades, formulando consultas y comentarios, aprobando las iniciativas del alcalde. En Panguipulli intervinieron en 59 oportunidades, presentando iniciativas, aportando informaciones, deliberando, y aprobando iniciativas.

Panguipulli disponía de una estructura municipal de mayor complejidad, donde la planificación y la gestión medioambiental estaban unidas (Figura 5). Además, tenía canales institucionalizados para la interacción entre las direcciones y los departamentos que 
cumplían funciones en la gestión de riesgos, y mantenía comités técnicos que promovían la coordinación y el trabajo interdepartamental. La Secretaría de Planificación (Secpla) de Panguipulli tenía un Departamento de Planificación Territorial y Ambiental que asesoraba al Concejo Municipal con el monitoreo e informes sobre la situación medioambiental de la comuna, los recursos hídricos y la postulación de proyectos. El municipio contaba con un sistema de comités técnicos para coordinar las actividades de las diferentes direcciones y departamentos, con funciones de análisis de políticas, planes, programas y proyectos, revisión de procedimientos administrativos, evaluación del cumplimiento de metas y asesoría a las unidades. Esta instancia apoyaba la circulación de información y el trabajo interdepartamental. En Cauquenes las oficinas de medioambiente y emergencias estaban ubicadas en la dirección de desarrollo comunitario (Dideco), aisladas, sin relación con la planificación ni otras dimensiones de la gestión municipal.

Figura 5

Esquema simplificado de la organización municipal en Panguipulli

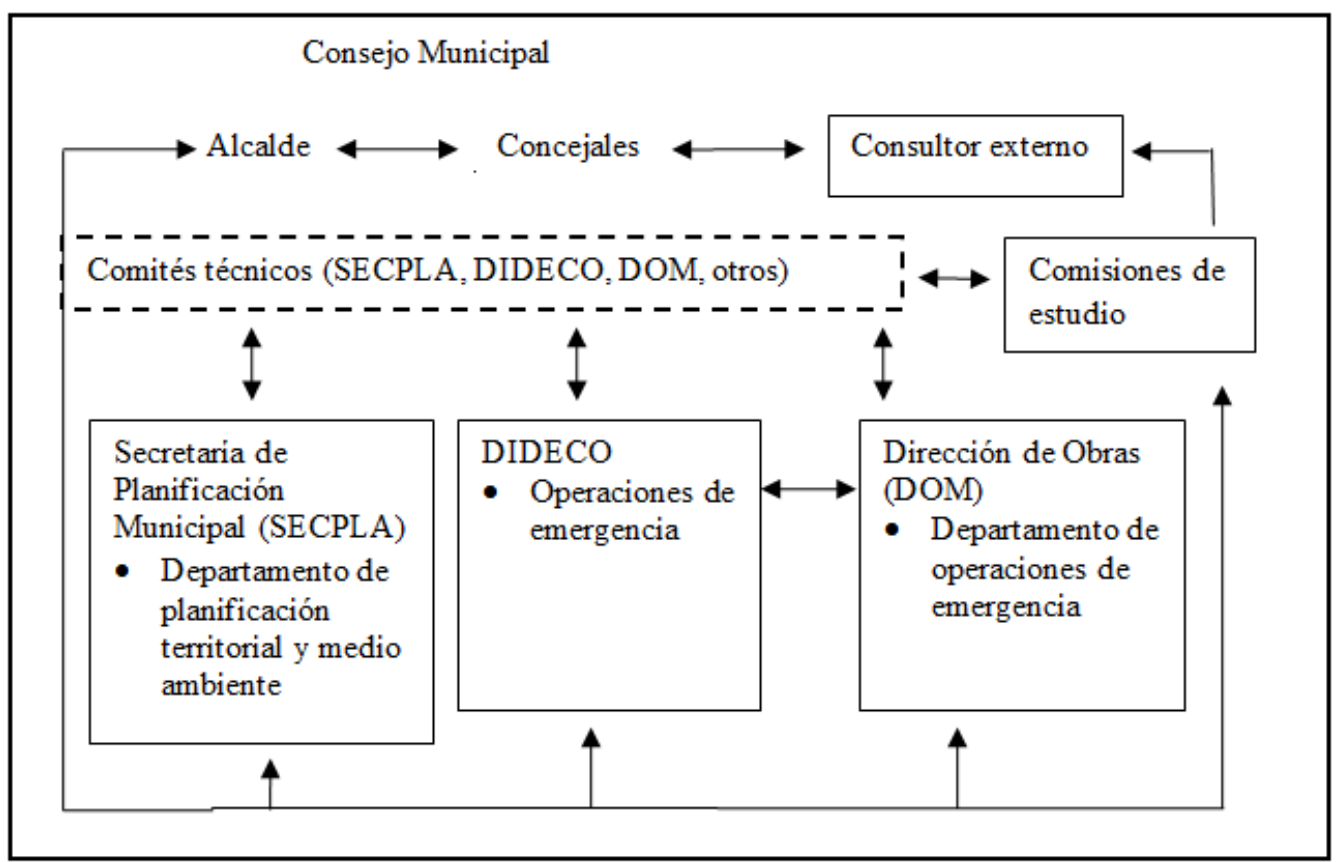

Fuente: Reglamento interno y organigrama municipal; entrevistas a funcionarios municipales.

Los modelos de regresión apoyan con evidencias cuantitativas la expectativa de efectos de la organización municipal. En los modelos 1 y 3 (Cuadros 1 y 3), las variables "Independencia del Concejo" y "Organización Interna" afectan positivamente la inversión medioambiental y los presupuestos de emergencia. Un aumento de una unidad en el índice de Independencia del Concejo está asociada a un incremento de la inversión en protección medioambiental, entre 1,352 y 1,355 ul (significancia al $p<0.05$ ), y en el aumento de los 
gastos en emergencia, entre 1,093 y 1,156 ul (significancia al $p<0.05$ ). Asimismo, una unidad de aumento en el índice de Organización Interna conduce tanto a un aumento de los gastos de emergencia, entre 6,744 y 6,835 ul (significancia al p < 0.01), como al aumento de la protección medioambiental en 1,806 ul (significancia al p < 0.05).

\section{Capacidades institucionales}

Los análisis cualitativo y cuantitativo apoyan la expectativa convencional que las capacidades institucionales, en particular los recursos financieros y humanos, explican comportamientos municipales.

En los dos casos de estudio, los funcionarios destacaron la importancia del presupuesto y el personal para GMRRD (entrevistas junio y agosto del 2014, ver A2 del Apéndice). En Cauquenes la oficina de medioambiente carecía de personal especializado y no estaba en condiciones de generar información que retroalimentara la política del municipio, y el funcionario responsable de las emergencias comunales contaba con el apoyo de solo un funcionario. En Panguipulli, el Departamento de Planificación Territorial y Ambiental disponía de siete profesionales para cumplir funciones, y el funcionario responsable de emergencia disponía de más personal para realizar sus actividades de prevención. En Panguipulli, esas capacidades institucionales eran reforzadas por una activa política de convenios con otras organizaciones que participaban en la gobernanza local (Valdivieso y Andersson, 2017).

Los resultados de los modelos de regresión muestran que un $1 \%$ de aumento de personal para GMRRD está asociado a un incremento en la inversión en protección medioambiental, entre 13,51 y 17,86 ul (significancia al $p<0.05-p<0.10$ ), y un aumento en la inversión en mitigación en 6,174 ul (significancia al $p<0.10$ ). Un aumento de un $1 \%$ del Fondo Común Municipal en el ingreso del municipio genera un decrecimiento de las inversiones en protección medioambiental y mitigación; en el caso de las primeras, en 0,0142 ul (significancia al $p<0.05$ ), y las segundas disminuyen entre 0,0690 y 0,00701 $u$ (significancia al $\mathrm{p}<0.05$ ).

\section{Capital social}

La interacción entre los gobiernos locales y la sociedad tiene efectos también en GMRRD, facilitando la circulación de información sobre el contexto comunal y en los riesgos, e influyen en los incentivos y las expectativas de los políticos locales.

En las entrevistas a hogares, las organizaciones sociales fueron identificadas como las formas de relación social que conectaban con el municipio. Quienes participaban en ellas tenían el propósito de alcanzar objetivos individuales y colectivos, tales como mejorar la infraestructura sanitaria, de vivienda y enfrentar problemas medioambientales. Al tener socios activos, estar registradas en la municipalidad y contar con personalidad jurídica, 
dichas organizaciones tenían la posibilidad de postular a beneficios, comunicar sus necesidades en el municipio e informarse sobre oportunidades. Además, ellas podían interactuar con el Concejo (correspondencia, audiencias, iniciativas en la comuna, etc.).

Los datos de las encuestas nacionales de caracterización socioeconómica Casen, aplicadas los años 2009, 2011 y 2013 (Ministerio de Desarrollo Social, 2014), informan sobre tasas de participación promedio de $19 \%$ en Cauquenes y $29 \%$ en Panguipulli. La participación social se concentraba en las juntas de vecinos y organizaciones religiosas, y Panguipulli destacó por el aumento de la participación de comunidades indígenas. Por otra parte, las tasas promedio de organizaciones territoriales y funcionales con personalidad jurídica por cada 1000 habitantes para el período 2009-2014 (Servicio de Registro Civil e Identificación, 2015) fueron las siguientes: 11,71 en Cauquenes y 21,68 en Panguipulli. Dado que las organizaciones adquieren personalidad jurídica con el propósito de recibir beneficios del municipio y de otros servicios públicos, Panguipulli era la comuna con mayor potencial para el desarrollo de CS bridging y linking y la interacción sinérgica con el municipio.

Durante un año (2014), en sus reuniones semanales, los concejos municipales de ambos municipios interactuaron con las organizaciones sociales en torno a temas de gestión medioambiental, emergencias comunales, vulnerabilidad y riesgos en las comunas. La interacción fue unidireccional cuando consistieron en la entrada o la salida de información; por ejemplo, los dirigentes de una organización social ingresaron una solicitud y el Concejo se informó sin pronunciarse sobre el asunto ni tomar medidas, o cuando el Concejo comunicó algo hacia fuera. En tanto que fue bidireccional cuando se produjo una interacción, por ejemplo, una organización ingresó una solicitud y el Concejo trató el tema, tomó una decisión y respondió apoyando o comprometiendo recursos municipales. Multidireccionales cuando el Concejo, además de involucrarse en la relación bidireccional, interactuó con un tercer actor, cuando la respuesta requirió la intervención de otra institución o generó una iniciativa de inversión. La circulación de información era más limitada en relaciones unidireccionales, comunicada en el Concejo con rapidez y sin consecuencias. En relaciones bidireccionales y multidireccionales, el alcalde y los concejales se pronunciaban, opinaban, aportan antecedentes, y deliberaban hasta tomar decisiones.

Panguipulli destacó por la cantidad, variedad y calidad de esas relaciones. En Cauquenes, las relaciones de las organizaciones sociales con el Concejo consistieron en solicitudes para obtener beneficios o información puntual de riesgo, tal como la proliferación de basura o caminos en mal estado. En Panguipulli fueron más frecuentes las audiencias con organizaciones sociales de base y organizaciones no gubernamentales, como también la intervención de concejales en representación de organizaciones sociales. Los flujos de información generaban intercambios de opinión en el Concejo, y propuestas de proyectos en GMRRD. 
El año 2014, Cauquenes registró cuatro inquietudes sociales sobre contaminación, una situación de emergencia por inundaciones, solicitudes de reparación de caminos y obras de extracción de agua de pozos profundos (déficit hídrico) (Municipalidad de Cauquenes, 2014). Panguipulli registró tres sobre situaciones de emergencia por nevadas (Municipalidad de Panguipulli, 2014). En todos los casos, los afectados se movilizaron, los funcionarios municipales informaron y los concejos municipales aprobaron gastos.

En diez oportunidades juntas de vecinos, comités de agua potable y de adelanto de Panguipulli informaron "acciones comunitarias" para mejorar caminos, gestionar recursos hídricos, reciclaje comunitario, manutención y limpieza de espacios públicos y soluciones habitacionales, con el propósito de enfrentar problemas medioambientales y prevenir situaciones de riesgo, y esas iniciativas fueron integradas en la cartera de proyectos de inversión del municipio (Municipalidad de Panguipulli, 2014). La información motivó la revisión de la gestión municipal para enfrentar la emergencia, visitas de los concejales a los lugares afectados, elaboración de informes sobre contaminación y recursos hídricos, y acciones de fiscalización (Municipalidad de Panguipulli, 2014). En cuatro oportunidades, las intervenciones de las organizaciones dieron lugar a la revisión de planes, programas y políticas de gestión de residuos sólidos, composta y condiciones para enfrentar emergencias, y la difusión radial para incentivar la corresponsabilidad de los vecinos en la manutención de los espacios públicos. En tres oportunidades, la inquietud motivó la realización de estudios sobre agentes contaminantes, topografía de suelos, recursos hídricos y situación legal del agua para el consumo humano.

En esa situación, las acciones del municipio consistieron en visitas del alcalde, concejales y funcionarios del municipio, elaboración de informes sobre contaminación y gestión de los recursos hídricos en diversos sectores de la comuna, fiscalización de actividades productivas contaminantes, denuncias de empresas contratistas por el mal estado de las obras finalizadas, así como el contacto con servicios públicos y ministerios para solicitar apoyo y acciones. En cuatro oportunidades, la intervención social dio lugar a la revisión de planes, programas y políticas de gestión de residuos sólidos, composta y condiciones para enfrentar emergencias, difusión radial y la certificación medioambiental de la comuna. En tres oportunidades, las inquietudes motivaron estudios sobre agentes contaminantes, topografía de suelos, recursos hídricos y situación legal del agua para el consumo humano.

La bidireccionalidad y los efectos de esas relaciones en las prácticas y acciones del Concejo Municipal se manifestaron en las actividades de los concejeros y del alcalde, la circulación de información sobre necesidades de mitigación por riesgos medioambientales específicos, tales como contaminación, y el apoyo con información sobre procedimientos y oportunidades para que las organizaciones sociales alcanzaran sus propósitos (Municipalidad de Panguipulli, 2014).

Algunas acciones de organizaciones no gubernamentales dieron lugar a estudios y acciones de mitigación destinadas a controlar fuentes contaminantes y la protección de los 
bosques (Municipalidad de Panguipulli, 2014). La información de la Corporación de Bosque Modelo Panguipulli y un reporte de la asociación Epu Rumen Sugun sobre contaminación y otros efectos negativos derivados de actividades forestales motivaron el análisis de material fotográfico con evidencias sobre la variación en la composición de los bosques y de los recursos hídricos en la comuna, y un estudio encargado a la Universidad Austral de Chile (Municipalidad de Panguipulli, 2014). Dos reportes del Comité para el Monitoreo y Protección del Lago Panguipuli y de las Organizaciones Sociales del Borde Costero motivaron la realización de estudios y análisis sobre factores contaminantes, topografía y suelos, ordenamiento territorial, ocupación y el uso del borde costero, y gestiones ante el Ministerio de Medio Ambiente para la protección de las aguas con normas secundarias de calidad ambiental de protección ecosistémica (Municipalidad de Panguipulli, 2014). La corporación Kom Newen Mapu difundió en el Concejo conocimientos sobre los alcances del Convenio 169 de la Organización Internacional del Trabajo y la Declaración de Naciones Unidas de las comunidades indígenas, y obtuvo un espacio institucional para un proyecto de capacitación (Municipalidad de Panguipulli, 2014). El Centro de Estudios Ambientales de la Universidad Austral informó al Concejo sobre la percepción de riesgos medioambientales, condiciones y necesidades para el turismo cultural y sustentable en la comuna (Municipalidad de Panguipulli, 2014).

Los resultados del análisis cuantitativo apoyan la idea que la participación social y el CS linking enriquecen la GMRRD. En el modelo 3 (Cuadro 3) un 1\% de aumento de la participación en organizaciones sociales de la comuna está asociado al incremento de los fondos de emergencia entre 1.094 y 1.133 ul (significancia al $p<0.01$ y al $p<0.10$ ). Por cada organización social registrada entre cada mil habitantes (Cuadros 1 y 2), la inversión en protección medioambiental y mitigación aumenta en 0.0162 ul en promedio (significancia al $\mathrm{p}<0.05$ ).

\section{Conclusiones}

El examen de las hipótesis en el contexto empírico chileno demuestra que la gestión medioambiental y de reducción de riesgos de desastres (GMRRD) es modelada por procesos político-institucionales, en particular como actúan los agentes que toman decisiones, sus relaciones de poder, como se organizan las instituciones, las capacidades institucionales, y los impulsos que proceden de la sociedad. Las informaciones y los análisis documentan que los factores políticos, los arreglos institucionales, las capacidades del municipio y la interacción con la sociedad afectan las estructuras de incentivos de los políticos locales, las decisiones de los gobiernos locales, y las acciones en la GMRRD.

Los resultados del análisis configuracional y cuantitativo permiten observar que en los casos investigados las trayectorias e ideologías de los alcaldes, los balances de poder en los concejos municipales, los reglamentos internos, y los procedimientos y las estructuras organizacionales municipales tienen efectos en las decisiones de los concejos 
municipales, y ayudan a explicar diferentes comportamientos en GMRRD. Un factor de particular interés del análisis cualitativo es el liderazgo de un agente con la capacidad de promover el cambio institucional. En el caso de Panguipulli, la intervención intencionada de un alcalde con valores, visiones, propósitos, y una estrategia efectiva fue crucial para la GMRRD. Por otra parte, los hallazgos del análisis del caso de Panguipulli, reforzados por las evidencias cuantitativas, demuestran que las relaciones sinérgicas entre las instituciones locales y la sociedad (CS linking) son de particular importancia para la GMRRD. La información y las inquietudes sociales aportan conocimientos sobre las condiciones medioambientales de la comuna, los riesgos, los recursos sociales movilizados, transmiten flujos de información y motivan acciones concretas.

Los resultados del estudio revelan la complejidad y el dinamismo que tienen las instituciones en contextos empíricos del mundo real. Tanto en el análisis de casos como en el análisis cuantitativo, observamos que no es únicamente un factor el que explica las decisiones, sino la combinación de condiciones que van configurando las decisiones y acciones en GMRRD. Por ejemplo, la trayectoria institucional, los arreglos institucionales y reglas operacionales que entran en sintonía con impulsos del capital social linking, explican decisiones y resultados en Panguipulli. Los datos de los cuadros con los modelos de regresión muestran varios factores afectando simultáneamente la GMRRD.

Estos hallazgos demuestran que los esfuerzos de investigación y las intervenciones en políticas públicas locales con enfoques y métodos que den la posibilidad de tener una perspectiva multisistémica sobre la configuración de condiciones institucionales que modelan las decisiones tienen mayor posibilidad de obtener resultados eficaces en términos de adaptación que enfoques mono-causales centrados en un supuesto factor que explica las decisiones y los resultados en las organizaciones.

Patricio Valdivieso - Profesor titular e investigador, Centro de Estudios del Desarrollo Regional y Políticas Públicas, Universidad de los Lagos; investigador asociado, Millennium Institute for Research in Market Imperfections and Public Policy (MIPP), Departamento de Ingeniería, Facultad de Ciencias Físicas y Matemáticas, Universidad de Chile; director, Núcleo de Desarrollo Regional, Local y Gobernanza Medioambiental N01/16, Universidad de los Lagos. E-mail: <pvaldivf@gmail.com>4 .

\footnotetext{
4 Valdivieso agradece el apoyo financiero del Fondo Nacional de Investigaciones Científicas y Tecnológicas, Proyecto Fondecyt no 1140672, y el apoyo financiero del Institute for Research in Market Imperfections and Public Policy (MIPP), ICM IS130002, Conicyt, y agradece a Benjamin Villena-Roldan por el apoyo y por responder numerosas consultas técnicas para el análisis cuantitativo.
} 


\section{Referencias bibliográficas}

ADGER, W. N. "Social capital, collective action and adaptation to climate change". Economic Geography, vol. 79, n 4, p. 387-404, 2003.

Adger, W. N., et al. "Are there social limits to adaptation to climate change?". Climatic Change, vol. 93, p. 335-354, 2009.

Agrawal, A.; Ribot, J. "Accountability in decentralization". The Journal of Developing Areas, vol. 33, n०4, p. 473-502, 1999.

Ahn, T. K.; OStrom, E. Social capital and collective action. In: Castiglione, D.; Van Deth, J.; Wolleb, G. (eds.). Handbook of social capital. Oxford: Oxford University Press, 2008.

AKLIN, M., et al. "Political competition, path dependence, and the strategy of sustainable energy transitions". American Journal of Political Science, vol. 57, n 3, p. 643-658, 2013.

ALDRICH, D. "The externalities of social capital: post-tsunami recovery in Southeast India". Journal of Civil Society, vol. 8, $\mathrm{n}^{\circ} 1$, p. 81-99, 2011.

Amsteins, K. Monitoreo ambiental. Universidad Austral, Facultad de Ciencias Forestales y Recursos Naturales, 2013. Disponible en:

<http://cybertesis.uach.cl/tesis/uach/2013/fifa528m/doc/fifa528m.pdf>. Acceso en: 23 nov. 2017.

Andersson, K. P.; VAN Laerhoven, F. "From local strongman to facilitator: institutional incentives for participatory municipal governance in Latin America". Comparative Political Studies, vol. 40, n 9, p. 1.085-1.111, 2007.

ANGUELOVSKI, I.; CARMIN, J. "Something borrowed, everything new: innovation and institutionalization in urban climate governance". Current Opinion in Environmental Sustainability, vol. 3, n 3, 169-175, 2011.

ARAVenA, R. Extractos entrevista de radio Panguipulli y Radio 102.1 al candidato de la alianza para alcalde en Panguipulli, René Aravena Riffo. El Diario de Panguipulli, 2008. Disponible en:

<www.eldiariopanguipulli.cl/notas/10\%20octubre\%2008/01/rene\%20aravena\%20alianza.htm>. Acceso en: 23 nov. 2017.

Berdegué, J., et al. "Ciudades rurales (2010)". Disponible en: <http://www.rimisp.org/>. Acceso en: 23 nov. 2017.

BETSILL, M. "Mitigating climate change in US cities: opportunities and obstacles". Local Environment, vol. 6, n०4, p. 393-406, 2001.

BURCH, S. "Transforming barriers into enablers of action on climate change: insights from three municipal case studies in British Columbia, Canada". Global Environmental Change, vol. 20, n 2, p. 287-297, 2010.

CAREY, M., et al. "An integrated socio-environmental framework for glacier hazard management and climate change adaptation: lessons from Lake 513, Cordillera Blanca, Peru". Climatic Change, vol. 112, p. 733-767, 2012.

CARMin, J.; ANGUelovski, I.; RoBertS, D. "Urban climate adaptation in the global south: planning in an emerging policy domain", Journal of Planning Education and Research, vol. 32, n 1, p. 18-32, 2012. 
CASHMORE, M.; WEJS, A. "Constructing legitimacy for climate change planning: a study of local government in Denmark". Global Environmental Change, vol. 24, n 1, p. 203-212, 2014.

CHEN, H.; WANG, J.; HUANG, J. "Policy support, social capital, and farmers' adaptation to drought in China". Global Environmental Change, vol. 24, p. 193-202, 2014.

CONAF - CORPORACión NACIONAL Forestal. "Estadísticas históricas 2014". Disponible en:

<http://www.conaf.cl/incendios-forestales/incendios-forestales-en-chile/estadisticas-historicas/>. Acceso en: 23 nov. 2017.

DECRETO No 156. "Aprueba plan nacional de proteccion civil, y deroga decreto no 155, de 1977", 2002. Disponible en: <https://www.leychile.cl/Navegar?idNorma=199115>. Acceso en: 23 nov. 2017.

DesinVentar - Disaster Information MANAGEMEnt SyStem. Chile database, 2014. Disponible en: <http://www.desinventar.net/index_www.html> Acceso en: 23 nov. 2017.

DupUis, J.; BIESBROECK, R. "Comparing apples and oranges: the dependent variable problem in comparing and evaluating climate change adaptation policies". Global Environmental Change, vol. 23, n 6, p. 1.476-1.487, 2013.

DYNES, R. "The importance of social capital in disaster response". Disaster Research Center, 2002. Disponible en: <http://dspace.udel.edu:8080/dspace/bitstream/handle/19716/292/PP\%20327. pdf?sequence $=1>$. Acceso en: 23 nov. 2017.

ELMORE, R. "Organizational models of social program implementation". Public Policy, vol. 26, n 2, p. 185-228, 1978.

ETKIN, D.; Medalye, J.; HiguCHI, K. "Climate warming and natural disaster management: an exploration of the issues". Climatic Change, vol. 112, p. 585-599, 2012.

FREITAG, M. "Bowling the state back in: political institutions and the creation of social capital". European Journal of Political Research, vol. 45, n 1, p. 123-152, 2006.

Gebremedhin, B.; Pender, J.; Tesfay, G. "Community natural resource management: the case of woodlots in Northern Ethiopia". Environment and Development Economics, vol. 8, p. 129-148, 2003.

HARRIES, T.; Penning-RowselL, E. "Victim pressure, institutional inertia and climate change adaptation: the case of flood risk". Global Environmental Change, vol. 21, n 1, p. 188-197, 2011.

Heltberg, R.; Siegel, P. B.; Jorgensen, S. J. "Addressing human vulnerability to climate change: toward a 'no-regrets' approach". Global Environmental Change, vol. 19, nº 1, p. 89-99, 2009.

Holgate, C. "Factors and actors in climate change". Local Environment, vol. 12, n 5, p. 471-484, 2007.

INGOLD, K.; FISCHER, M. "Drivers of collaboration to mitigate climate change: an illustration of Swiss climate policy over 15 years". Global Environmental Change, vol. 24, p. 88-98, 2014.

INE - INSTITUTO NACIONAL DE ESTADÍSTICAS. "Censos y estadísticas de población y vivienda". Disponible en: <http://www.ine.cl>. Acceso en: 23 nov. 2017.

INIA - InStituto NACiONAL DE InVestigaciones Agropecuarias. "Red de estaciones meteorológicas". Disponible en: <http://agromet.inia.cl/estaciones.php>. Acceso en: 23 nov. 2017.

ipCC - Panel Intergubernamental del CAmbio Climático. Managing the risks of extreme events and disasters to advance climate change adaptation. Cambridge: Cambridge University Press, 2012. 
ipCC - Panel intergubernamental del Cambio Climático. Climate change 2013: impacts, adaptation, and vulnerability. Part A. Cambridge: Cambridge University Press, 2013.

JONES, C. "Social capital and climate change mitigation in coastal areas: a review of the current debates and identification of future research directions". Ocean Coast Manage, vol. 80, p. 12-19, 2013.

KEOGH, D., et al. "Resilience, vulnerability and adaptive capacity of an inland rural town prone to flooding: a climate change adaptation case study of Charleville, Queensland, Australia". Nat Hazards, vol. 59, n² 2, p. 699-723, 2011.

LARSEN, S. V.; KøRnøV, L.; WeJS, A. "Mind the gap in SEA: an institutional... Areas are missing". Environmental Impact Assessment Review, vol. 33, n 1, p. 32-40, 2012.

Lin, N. A network theory of social capital. In: Castiglione, D.; Van Deth, J.; Wolleb, G. (eds.). Handbook of social capital. Oxford: Oxford University Press, 2008.

MAguire, S.; HARdY, C.; LAWRENCE, T. "Institutional entrepreneurship in emerging fields: HIV/Aids treatment advocacy in Canada". Academy of Management Journal, vol. 47, n 5, p. 657-679, 2004.

MARIN, A.; VALDIVIESO, P. "Exploring governance networks for disaster risk reduction: insights and challenges from rural municipalities in Center-South of Chile". Artículo en progreso, Proyecto no Fondecyt 1140672, 2016.

Ministerio de Agricultura. "Base de datos de emergencias agrícolas (2014)". Facilitada por Unidad de Emergencias Agrícolas, 25 ene. 2015.

Ministerio de Desarrollo Social. "Bases de datos de encuestas Casen". Observatorio, 2014.

Disponible en: <http://observatorio.ministeriodesarrollosocial.gob.cl>. Acceso en: 23 nov. 2017.

Municipalidad De Cauquenes. "Plan de Desarrollo Comunal 2010", 2010. Disponible en:

<https://www.portaltransparencia.cl/PortalPdT/pdtta?codOrganismo=MU033>. Acceso en: 23 nov. 2017.

. "Actas del Concejo Municipal 2014, nos 37, 16-04-2014; 40, 03-01-2014; 51, 56, 1006-2014; 47, 06-03-2014; 49, 01-04-2014; 61, 05-08-2014; 63, 12-08-2014; 64, 02-09-2014; 67, 09-10-2014; 70, 04-11-2014", 2014. Disponible en: <http://www.cauquenes.cl/>. Acceso en: 23 nov. 2017.

. "Plan de Desarrollo Comunal 2014", 2014. Disponible en:

<https://www.portaltransparencia.cl/PortalPdT/pdtta?codOrganismo=Mu033>. Acceso en: 23 nov. 2017.

. "Plan de Desarrollo Comunal 2014-2018", 2014. Disponible en:

<https://www.portaltransparencia.cl/PortalPdT/pdtta?codOrganismo=MU033>. Acceso en: 23 nov. 2017.

Municipalidad de Panguipulli. "Diagnóstico Comuna de Panguipulli". Agenda 21 Local. Valdivia: Programa Eco-Región de Los Lagos Sustentable, 2004.

"Actas del Concejo Municipal 2004-2008", 2008. Disponible en:

<http://municipalidadpanguipulli.cl/>. Acceso en: 23 nov. 2017.

. "Plan de Desarrollo Comunal 2008", 2008. Disponible en:

<http://www.panguipullitransparente.cl>. Acceso en: 23 nov. 2017. 
Municipalidad de Panguipulli. "Plan de Desarrollo Comunal 2013", 2013. Disponible en: <http://www.panguipullitransparente.cl>. Acceso en: 23 nov. 2017.

Municipalidad de Panguipulli. "Actas del Concejo Municipal 2014, nos 2, 21-01-2014; 4, 04-02-2014; $5,26-02-2014 ; 9,24-03-2014 ; 11,08-04-2014 ; 13,29-04-2014 ; 16,20-05-2014 ; 18,30-05-$ $2014 ; 18,30-05-2014 ; 19,10-06-2014 ; 20,17-06-2014 ; 23,23-06-2014 ; 27,12-08-2014 ; 29,26-$ 08-2014; 34, 14-10-2014; 35, 21-10-2014; 37, 28-10-2014", 2014. Disponible en: <http://municipalidadpanguipulli.cl/>. Consultado entre 20 enero al 30 de marzo 2015.

MuÑoz, J. C. "Aclamación del Alcalde in Cauquenes". La Prensa, 2012. Disponible en: <http://www.diariolaprensa.cl/region/aclamacion-para-alcalde-de-cauquenes/>. Acceso en: 23 nov. 2017.

NoRRIS, F. H., et al. "Community resilience as a metaphor, theory, set of capacities, and strategy for disaster readiness". American Journal of Community Psychology, vol. 41, p. 127-150, 2008.

Ostrom, E. Governing the commons. Cambridge: Cambridge University Press, 1990.

PASQUiNi, L.; ShEARING, C. "Municipalities, politics, and climate change: an example of the process of institutionalizing an environmental agenda within local government". The Journal of Environment \& Development, vol. 23, n², p. 271-296, 2014.

Pelling, M.; High, C. H. "Understanding adaptation: what can social capital offer assessments of adaptive capacity?". Global Environmental Change, vol. 15, p. 308-319, 2005.

Portney, K. E.; Berry, J. "Civil society and sustainable cities". Comparative Political Studies, vol. 47, $\mathrm{n}^{\circ} 3$, p. 395-419, 2014.

PNUD - Programa de Naciones Unidas Para el DeSARrollo. Índice de Desarrollo Humano (2003). Disponible en: <http://desarrollohumano.cl/idh/bases-datos/pnud-idh-2006/>. Acceso en: 23 nov. 2017.

RUBIN, O. "The burden of excessive 'linking social capital' evidence from four Vietnamese provinces". Asian Journal of Social Science, vol. 43, $\mathrm{n}^{\circ}$ 6, p. 760-785, 2015.

SABatier, P. A., et al. Policy change and learning: an advocacy coalition approach. Boulder: Westview Press, 1993.

SÁnCHEZ, R. "La debilidad de la gestión del riesgo en los centros urbanos. El caso del área metropolitana de Santiago de Chile". Norte Grande, 2010. Disponible en:

<http://www.scielo.cl/pdf/rgeong/n47/art01.pdf>. Acceso en: 23 nov. 2017.

SANTA MARÍA, H., et al. "Plan de protección civil: sistema de evaluación estructural rápida post-sismo de edificios e infraestructura". Políticas Públicas, 2010. Disponible en:

<http://politicaspublicas.uc.cl/wp-content/uploads/2015/02/plan-de-proteccion-civil.pdf>. Acceso en: 23 nov. 2017.

SATTERTHWAITE, D. "Climate change and urbanization: effects and implications for urban governance". Conferencia, 2008. Disponible en:

<http://www.un.org/esa/population/meetings/EGM_PopDist/P16_Satterthwaite.pdf>. Acceso en: 23 nov. 2017.

Servel - Servicio Electoral. "Resultados electorales en comunas 2012". Disponible en: <http://www.servel.cl>. Acceso en: 23 nov. 2017. 
Servicio de Registro Civil e Identificación. Base de datos de organizaciones con personalidad jurídica. Personas jurídicas, 2015. Disponible en: <http://www.registrocivil.cl>. Acceso en: 23 nov. 2017.

Sinim - SeRvicio Nacional De Información Municipal. "Datos municipales 2014", 2014. Disponible en: <http://www.sinim.cl>. Acceso en: 23 nov. 2017.

Subdere - Subsecretaría de Desarrollo Regional y Administrativo, Ministerio del Interior y Seguridad Pública. "Territorios aislados (2011)", 2011. Disponible en: <http://www.subdere.gov.cl/>. Acceso en: 23 nov. 2017.

SZRETER, S.; WOoLCOCK, M. "Health by association? Social capital, social theory, and the political economy of public health". International Journal of Epidemiology, vol. 33, n 4, p. 650-667, 2004.

VALDIVIESO, P. "Municipal governance, environmental management and disaster risk reduction in Chile". Bulletin of Latin American Research, vol. 36, p. 440-458, dic. 2016.

VALDIVIESO, P.; ANDERSSON, K. P. "Local politics of environmental disaster risk management: institutional analysis and lessons from Chile". Journal of Environment \& Development, vol. $26, \mathrm{n}^{\circ} 1$, p. 51-81, 2017.

VALdivieso, P.; ANDERsSON, K. P.; VillenA-RoldÁn, B. "Institutional drivers of adaptation in local government decision-making: evidence from Chile". Climatic Change, vol. 143, p. 157-171, 2017.

Valdivieso, P.; FonseCA, F. "Capacidad de adaptación de los gobiernos locales ante los efectos del cambio climático - Propuestas para una agenda de investigación". In: Anais do 70 Encontro da Associação Nacional de Pós-Graduação e Pesquisa em Ambiente e Sociedade, Brasilia, 2015.

VERVISCH, T.; TITECA, K. "Bridging community associations in post-conflict Burundi: the difficult merging of social capital endowments and new institutional settings". The Journal of Modern African Studies, vol. 48, n³, p. 485-511, 2010.

Waters, E.; Barnett, J.; Puleston, A. "Contrasting perspectives on barriers to adaptation in Australian climate change policy". Climatic Change, vol. 124, p. 691-702, 2014.

Wolf, J., et al. "Social capital, individual responses to heat waves and climate change adaptation: an empirical study of two UK cities". Global Environmental Change, vol. 20, p. 44-52, 2010.

WOOLCOCK, M.; NARAYAN, D. "Social capital: implications for development theory, research, and policy". World Bank Research Observer, vol. 15, n², p. 2-49, 2000.

WORLD BANK. Country note on climate change aspects in agriculture. World Bank, 2009. Disponible en: <http://siteresources.worldbank.org/INTLAC/Resources/Climate_ChileWeb.pdf>. Acceso en: 23 nov. 2017. 


\section{Apéndices}

\section{Cuadro A1 \\ Fuentes primarias consultadas}

\begin{tabular}{|c|c|c|}
\hline \multicolumn{3}{|c|}{ 1. Documentación municipal y datos } \\
\hline \multicolumn{3}{|c|}{ 1.1. Cuentas municipales anuales de los alcaldes, 2008-2014 } \\
\hline \multicolumn{3}{|c|}{ 1.2. Planes de desarrollo comunal, $2008-2014$} \\
\hline \multicolumn{3}{|l|}{ 1.3. Reglamentos, 2008-2014 } \\
\hline \multicolumn{3}{|c|}{ 1.4. Reglamentos del Concejo Municipal, 2008-2014 } \\
\hline \multicolumn{3}{|c|}{ 1.5. Organigramas municipales, 2008-2014 } \\
\hline \multicolumn{3}{|c|}{ 1.6. Registros de reuniones de los concejos municipales, 2014} \\
\hline \multicolumn{3}{|c|}{ 1.7. Ordenanzas, $2008-2014$} \\
\hline \multicolumn{3}{|c|}{ 1.9. Presupuestos municipales anuales, 2008-2014 } \\
\hline \multicolumn{3}{|c|}{ 1.10. Proyectos de inversión ingresados en el sistema nacional de inversiones, 2009-2014 } \\
\hline \multicolumn{3}{|c|}{ 1.11. Personal municipal (estudios, funciones, otros), 2009-2014 } \\
\hline \multicolumn{3}{|c|}{ 1.12. Planes de ordenamiento territorial, $2008-2014$} \\
\hline \multicolumn{3}{|c|}{ 1.13. Regulaciones de participación social, 2008-2014 } \\
\hline \multicolumn{3}{|c|}{ 2. Documentación pública y bases de datos } \\
\hline \multicolumn{3}{|l|}{ 2.1. Bases de datos territorial } \\
\hline \multicolumn{3}{|c|}{ 2.2. Sistema nacional de información municipal, estadísticas municipales } \\
\hline \multicolumn{3}{|c|}{ 2.3. Sistema nacional de información municipal, ejecución presupuestaria cuarto trimestre 2008-2014 } \\
\hline \multicolumn{3}{|c|}{ 2.4. Encuestas de caracterización socioeconómica Casen, 2009, 2011 y 2013} \\
\hline \multicolumn{3}{|c|}{ 2.5. Organizaciones con personalidad jurídica, Servicio de Registro Civil e Identificación 2013, 2014} \\
\hline \multicolumn{3}{|c|}{$\begin{array}{l}\text { 2.6. Estaciones de monitoreo del clima en red Inia, Servicio Meteorológico de Chile, con información } \\
\text { diaria, mensual, y anual 2009-2014 }\end{array}$} \\
\hline \multicolumn{3}{|c|}{$\begin{array}{l}\text { 2.7. Base de datos Desinventar con registros de eventos extremos en las comunas chilenas, } 1970-2011 \\
\text { (lluvias, inundaciones, sequías, terremotos, tsunamis, erupciones volcánicas, incendios forestales) }\end{array}$} \\
\hline \multicolumn{3}{|c|}{$\begin{array}{l}\text { 2.8. Incendios forestales por comunas (numero, cantidad de hectáreas afectadas), base de datos de la } \\
\text { Corporación Nacional Forestal, 2008-2014 }\end{array}$} \\
\hline \multicolumn{3}{|c|}{ 2.9. Estadísticas medioambientales, Instituto Nacional de Estadísticas, 2008-2014 } \\
\hline \multicolumn{3}{|c|}{$\begin{array}{l}\text { 2.10. Base de datos con indicadores de aislamiento en las comunas chilenas, Subdere del Ministerio del } \\
\text { Interior y Seguridad Pública, } 2007 \text { y } 2012\end{array}$} \\
\hline \multicolumn{3}{|c|}{ 2.11. Indicadores de desarrollo humano, Programa de las Naciones Unidas para el Desarrollo, 2003} \\
\hline 3. Entrevistas & Cauquenes & \\
\hline 3.1. Funcionarios municipales & 5 & \\
\hline 3.2. Dirigentes sociales & 5 & \\
\hline 3.3. Jefes de hogar & 48 & \\
\hline 3.4. Focus groups & 3 & \\
\hline
\end{tabular}


Cuadro A2

Registros de entrevistas semi-estructuradas y grupos de discusión en Cauquenes y Panguipulli (2014-2016)

\begin{tabular}{|c|c|c|c|c|c|c|}
\hline & Localidad & Población & Jefes de hogar & $\begin{array}{c}\text { Dirigentes } \\
\text { sociales }\end{array}$ & $\begin{array}{l}\text { Funcionarios } \\
\text { municipales }\end{array}$ & $\begin{array}{c}\text { Grupos } \\
\text { discusión }\end{array}$ \\
\hline \multirow{20}{*}{ 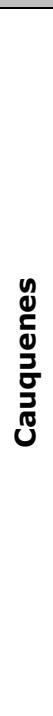 } & Plaza de Armas & 1.549 & 2 & & & \\
\hline & Regimiento & 3.188 & 3 & & & \\
\hline & Arturo Prat & 7.565 & 7 & 2 & 4 & 2 \\
\hline & Independencia & 1.272 & 2 & & & \\
\hline & Los Estanques & 3.687 & 3 & & 1 & \\
\hline & Barrio Estación & 8.220 & 11 & 2 & & \\
\hline & El Boldo & 289 & 1 & & & \\
\hline & Caracol & 567 & 1 & & & \\
\hline & Pedernales & 328 & 1 & & & \\
\hline & Sauzal & 1.341 & 3 & & & \\
\hline & Quella & 902 & 1 & & & \\
\hline & Pocillas & 758 & 1 & 1 & & 1 \\
\hline & San Antonio & 733 & 1 & & & \\
\hline & San Manuel & 591 & 1 & & & \\
\hline & Coronel del Maule & 1.004 & 1 & & & \\
\hline & Pillén & 6.240 & 5 & & & \\
\hline & Las Garzas & 2.518 & 2 & & & \\
\hline & Unihue & 221 & 1 & & & \\
\hline & Other & 244 & 1 & & & \\
\hline & Total & 41.217 & 48 & 5 & 5 & 3 \\
\hline \multirow{14}{*}{ 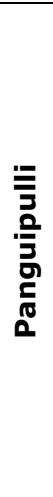 } & Panguipulli & 12.900 & 12 & 1 & 4 & 5 \\
\hline & Panguilelfún & 1.900 & 2 & & & \\
\hline & Calafquén & 3.000 & 6 & & & \\
\hline & Melefquén & 798 & 0 & & & \\
\hline & Coñaripe & 3.900 & 7 & 1 & & \\
\hline & Liquiñe & 3.166 & 7 & & & \\
\hline & Choshuenco & 838 & 0 & & & \\
\hline & Coihueco & 1.958 & 2 & & & \\
\hline & El Desagüe & 293 & 1 & & & \\
\hline & Correltué & 461 & 1 & & & \\
\hline & Neltume & 3.495 & 7 & 2 & & \\
\hline & Río Huahum & 135 & 0 & & & \\
\hline & Other & 68 & 0 & & & \\
\hline & Total & 32.912 & 46 & 4 & 4 & 5 \\
\hline
\end{tabular}

Fuentes: Registros de trabajo de campo del Proyecto Fondecyt no 1140672 (2014-2018). 


\section{Cuadro A3 \\ Percepciones de riesgo con muestra expandida al universo}

\begin{tabular}{|c|c|c|c|c|}
\hline \multirow{2}{*}{\begin{tabular}{|l|} 
Percepción de riesgos \\
\end{tabular}} & \multicolumn{2}{|c|}{ Cauquenes } & \multicolumn{2}{|c|}{ Panguipulli } \\
\hline & Frecuencia & Porcentaje & Frecuencia & Porcentaje \\
\hline \multicolumn{5}{|l|}{ Peligros medioambientales } \\
\hline Terremotos y erupciones & 14,053 & 96.0 & 11,110 & 87.6 \\
\hline Pestes (roedores, insectos, otros) & 9,249 & 63.0 & 5,387 & 34.8 \\
\hline Cambios en vegetación y bosques & 7,804 & 53.0 & 6,783 & 53.5 \\
\hline Clima (Iluvias, tormentas, sequías) & 4,345 & 30.0 & 10,119 & 79.8 \\
\hline Contaminación & 2,957 & 20.0 & & \\
\hline Inundaciones (tsunami, mar, ríos, lagos) & 1,881 & 13.0 & 7,059 & 55.6 \\
\hline Otros & 767 & 5.0 & 6,057 & 47.7 \\
\hline \multicolumn{5}{|l|}{ Riesgos relacionados con el clima } \\
\hline Pestes & 9,879 & 68.0 & 5,387 & 34.8 \\
\hline Inundaciones por lluvias & 8,119 & 56.0 & 6,646 & 52.4 \\
\hline Incendios forestales & 7,644 & 52.0 & 8,874 & 70.0 \\
\hline Sequías & 4,120 & 28.0 & 9,123 & 71.9 \\
\hline Tormentas (viento, Iluvia, o nieve) & 3,984 & 27.0 & 7,478 & 59.0 \\
\hline Bajas temperaturas y heladas & 2,692 & 18.0 & 7,942 & 62.6 \\
\hline Inundaciones por tsunamis, mar, ríos, lagos) & 2,600 & 18.0 & 7,059 & 55.6 \\
\hline Altas temperaturas y olas de calor & 1,918 & 13.0 & 8,620 & 67.9 \\
\hline Movimientos de tierra & 578 & 4.0 & 7,016 & 55.3 \\
\hline \multicolumn{5}{|l|}{ Daños por desastres (experiencias encuestados) } \\
\hline Terremoto & 12,086 & 82.6 & & \\
\hline Sequías & 9,426 & 64.5 & 8,076 & 63.7 \\
\hline Pestes & 8,064 & 55.1 & 2,908 & 22.9 \\
\hline Inundaciones por lluvias & 7,570 & 51.8 & 2,995 & 23.6 \\
\hline Incendios forestales & 7,462 & 51.0 & 2,908 & 22.9 \\
\hline Bajas temperaturas y heladas & 6,672 & 45.6 & 8,273 & 65.2 \\
\hline Altas temperaturas y olas de calor & 4,377 & 29.9 & 7,545 & 59.5 \\
\hline Tormentas (viento y lluvia) & 4,267 & 29.2 & 4,798 & 37.8 \\
\hline Inundaciones (tsunami, mar, ríos, lagos) & 1,395 & 9.5 & 3,767 & 29.7 \\
\hline Aluviones & 1,003 & 6.9 & 4,079 & 32.2 \\
\hline Erupciones volcánicas & 408 & 2.8 & & \\
\hline \multicolumn{5}{|l|}{ Actividades económicas afectadas por el clima } \\
\hline Agricultura y base alimenticia & 13,613 & 93 & 8,060 & 63.5 \\
\hline Servicios comerciales (tiendas, shops) & 8,932 & 61.0 & 6,051 & 47.7 \\
\hline Pesca & 5,452 & 37.0 & 5,930 & 46.7 \\
\hline Explotación de bosques & 5,436 & 37.0 & 6,970 & 54.9 \\
\hline Turismo & 4,278 & 29.0 & 7,389 & 58.2 \\
\hline Industrias & 764 & 5.0 & 5,238 & 41.3 \\
\hline \multicolumn{5}{|l|}{ Condiciones de vida afectadas } \\
\hline Precios de productos agrícolas & 10,378 & 71.0 & 9,129 & 72.0 \\
\hline $\begin{array}{l}\text { Dificultades en sistemas de cultivo y } \\
\text { abastecimiento con productos agrícolas }\end{array}$ & 8,913 & 61.0 & 8,867 & 69.9 \\
\hline Cambios en hábitos alimenticios & 6,519 & 45.0 & 8,560 & 67.5 \\
\hline Problemas en caminos y transportes & 4,527 & 31.0 & 5,841 & 46.0 \\
\hline Almacenamiento de agua & 3,932 & 27.0 & 8,321 & 65.6 \\
\hline Enfermedades causadas por temperaturas & 3,347 & 23.0 & 8,301 & 65.4 \\
\hline Deterioro del material de las viviendas & 2,790 & 19.0 & 6,247 & 49.2 \\
\hline Problemas con abastecimiento de electricidad & 1,846 & 13.0 & 4,425 & 34.9 \\
\hline Problemas con drenaje e inundaciones & 844 & 6.0 & & \\
\hline Otros (plagas de ratones, sanitarios) & 278 & 2.0 & & \\
\hline
\end{tabular}

Fuente: Elaboración propia con bases de datos de encuestas aplicadas a muestras representativas de jefes de hogar (2015-2016) por el Proyecto Fondecyt nº 1140672 (2014-2018). 
Cuadro A4

Exposición, fragilidad socioeconómica, experiencia con eventos extremos

\begin{tabular}{|c|c|c|}
\hline \multirow[b]{2}{*}{ Atributos relacionados con riesgo } & \multicolumn{2}{|c|}{ Municipalidad } \\
\hline & Cauquenes & Panguipulli \\
\hline \multicolumn{3}{|l|}{ a) Caracterización } \\
\hline Geografía & Valle & Montaña \\
\hline Localización & $\left(35^{\circ} 58^{\prime} \mathrm{S} 72^{\circ} 21^{\prime} \mathrm{W}\right)$ & $\left(39^{\circ} 38^{\prime} \mathrm{S} 72^{\circ} 19^{\prime} \mathrm{W}\right)$ \\
\hline Superficie $\left(\mathrm{km}^{2}\right)$ & $2,126.3$ & 3,292 \\
\hline Población (2012) & 41,217 & 32,912 \\
\hline Rural (\%) & 33.5 & 60.0 \\
\hline Indígena (\%) & 1.3 & 40.83 \\
\hline \multicolumn{3}{|l|}{ b) Fragilidad socioeconómica } \\
\hline Económica & Alta & Alta \\
\hline \multicolumn{3}{|l|}{ Social } \\
\hline Indice de desarrollo humano (ranking) & Baja & Baja \\
\hline Educación primaria o menos (\%) & 55.2 & 59.0 \\
\hline Pobreza (\%) & 29.6 & 33.00 \\
\hline \multicolumn{3}{|l|}{ c) Capacidades municipales } \\
\hline Presupuesto anual dividido por habitantes & 136 & 210 \\
\hline Dependencia presupuestaria de transferencias externas (\%) & 44.6 & 43 \\
\hline Personal con títulos y grados (\%) & 19 & 33 \\
\hline \multicolumn{3}{|l|}{ d) Exposición } \\
\hline Percepciones & $\mathrm{Si}$ & Si \\
\hline Variabilidad climática & $\mathrm{Si}$ & Si \\
\hline Inundaciones & $\mathrm{Si}$ & Si \\
\hline Tectónicos & $\mathrm{Si}$ & Si \\
\hline Contaminación & $\mathrm{Si}$ & $\mathrm{Si}$ \\
\hline Incendios forestales & Si & Si \\
\hline Ocupación humana en lugares peligrosos & $\mathrm{Si}$ & Si \\
\hline Déficit en infraestructuras críticas & $\mathrm{Si}$ & Si \\
\hline Déficit en servicios básicos & $\mathrm{Si}$ & $\mathrm{Si}$ \\
\hline e) Experiencias con eventos extremos 1971-2011 & 33 & 24 \\
\hline Desastres declarados por el gobierno nacional, 2008-2014 & 3 & 4 \\
\hline Pérdidas debido a incendios (hectáreas), 2008-2014 & $17,999.85$ & $1,864.58$ \\
\hline
\end{tabular}

Fuente: Amsteins (2013); Berdegué et al. (2010); Municipalidad de Cauquenes (2010); Municipalidad de Cauquenes (2014); Conaf (2014); Desinventar (2014); INE; Inia; Ministerio de Agricultura (2014); Ministerio de Desarrollo Social (2014); Municipalidad de Panguipulli (2004); Municipalidad de Panguipulli (2008); Municipalidad de Panguipulli (2013); Sinim (2014); Subdere (2011) PNUD (2003); entrevistas Cuadro A2; encuestas aplicadas a muestras representativas de jefes de hogar en Cauquenes y Panguipulli por el proyecto Fondecyt no 1140672 (2014-2015). 


\section{Cuadro A5}

Características socioeconómicas con muestra ampliada al universo

\begin{tabular}{|c|c|c|c|c|}
\hline \multirow[b]{2}{*}{ Características socioeconómicas } & \multicolumn{2}{|c|}{ Cauquenes } & \multicolumn{2}{|c|}{ Panguipulli } \\
\hline & Frecuencia & Porcentaje & Frecuencia & Porcentaje \\
\hline \multicolumn{5}{|l|}{ Población } \\
\hline Urbana & 9,236 & 63.2 & 5,127 & 40.4 \\
\hline Rural & 5,388 & 36.8 & 7,559 & 59.6 \\
\hline \multicolumn{5}{|l|}{ Educación } \\
\hline Primaria o menos & 9,678 & 66.2 & 5,624 & 44.3 \\
\hline Secundaria & 3,32 & 22.8 & 4,403 & 34.7 \\
\hline Técnica o universitaria & 1,575 & 10.8 & 2,499 & 19.7 \\
\hline \multicolumn{5}{|l|}{ Ingreso (USD 2014) } \\
\hline Menos que 379 & 10,337 & 71.7 & 2,42 & 19 \\
\hline 397 a 873 & 3,411 & 23.3 & 4,8 & 37.8 \\
\hline Más que 874 & 875 & 6.0 & 5,465 & 34.4 \\
\hline \multicolumn{5}{|l|}{ Agua potable } \\
\hline Red pública & 11,659 & 79.7 & 7,287 & 57.4 \\
\hline Otros (rios, noria, pozo) & 2,965 & 20.3 & 5,399 & 42.6 \\
\hline \multicolumn{5}{|l|}{ Servicios sanitarios } \\
\hline Red pública & 11,358 & 77.7 & 4,895 & 38.6 \\
\hline Pozo negro o canal & 3,266 & 22.3 & 7,791 & 61.4 \\
\hline \multicolumn{5}{|l|}{ Contaminación del aire (invierno) } \\
\hline Algo & 3,998 & 27.3 & 306 & 2.4 \\
\hline Alta & 1,839 & 12.6 & & \\
\hline \multicolumn{5}{|l|}{ Contaminación del suelo (invierno) } \\
\hline Algo & 5,399 & 36.9 & 306 & 2.4 \\
\hline Alta & 1,2 & 8.2 & & \\
\hline \multicolumn{5}{|l|}{ Contaminación del agua (invierno) } \\
\hline Algo & 2,246 & 15.4 & 306 & 2.4 \\
\hline Alta & 705 & 4.8 & & \\
\hline \multicolumn{5}{|l|}{ Condición de calles y pavimentos } \\
\hline Malo & 3,769 & 25.8 & 6,706 & 52.9 \\
\hline Regular & 8,918 & 61.0 & 3,052 & 24.1 \\
\hline Bueno & 1,885 & 12.9 & 2,927 & 23.1 \\
\hline \multicolumn{5}{|l|}{ Condiciones por basura } \\
\hline Malo & 3,331 & 22.8 & 6,706 & 52.9 \\
\hline Regular & 8,202 & 56.0 & 3,052 & 24.1 \\
\hline Bueno & 2,513 & 17.2 & 2,927 & 23.1 \\
\hline
\end{tabular}

Fuente: Elaboración propia con bases de datos de encuestas aplicadas a muestras representativas de jefes de hogar (2015-2016) por el Proyecto Fondecyt no 1140672 (2014-2018). 


\section{Cuadro A6}

\section{Actividades de protección medioambiental en Cauquenes y Panguipulli}

\section{Acciones de gestión medioambiental ( $1=s i$ realiza, $0=$ no realiza)}

1.Educación ciudadana para la gestión medioambiental (por ejemplo en escuelas, enseñar cómo usar el agua, energías, otros)

2.Difusión de información (radios, prensa, folletos, sobre cuidado medioambiental)

3.Planes de gestión medioambiental (con protocolos a seguir, proyectos, otros)

4.Planes preventivos de adaptación al cambio climático (por ejemplo para sequias)

5. Obras de infraestructura para proteger el medio ambiente (ejemplo parques, protección de biodiversidad, otros)

6.Equipamiento especial para gestión medioambiental (computadores, softwares especializados, otros)

7.Monitoreo (agua, temperaturas, ríos y lagos, contaminación, otros)

8.Convenios de colaboración con organizaciones e instituciones

9. Actividades de protección medioambiental con organizaciones no gubernamentales (por ejemplo sistemas de monitoreo, proyectos, otros) 10. Actividades de protección medioambiental con organizaciones sociales (por ejemplo elaboración de actividades conjuntas, mesas territoriales, formación de monitores)

11.Contratación de servicios para protección medioambiental (por ejemplo contratistas o convenios con empresas)

12.Proyectos de inversión que ayuden a la protección medioambiental (que den ingresos, empleo, otros)

13.Proyectos con empresas o corporaciones que generen beneficio para el sector privado (empresas, entre otros)

14.Actividades institucionalizadas con la Secretaría de Planificación Comunal (ejemplo, oficina de medio ambiente que funciona en el Secpla, información medioambiental que sea usada por Secpla para proyectos, otro)

15. Actividades de protección medioambiental en varios departamentos del municipio (por ejemplo en DOM, Dideco y Secretaria Municipal) 16.Participación de oficina de medio ambiente o su equivalente en instancias de coordinación municipal (comités técnicos de directores de departamentos u otra instancia donde haya actividad de coordinación regular)

17.Interacciones regulares con el Concejo Municipal (por ejemplo comisión de estudio del Concejo Municipal, asistencia a reuniones del concejo)

18. Ordenanzas medioambientales (prohibición de ciertas actividades) 19. Actividades de reciclaje y compostaje Índice (proporción) Cauquenes Panguipulli

Fuentes: Elaboración propia con entrevistas semi-estructuradas aplicadas a funcionarios responsables del medioambiente (junio y agosto 2014) por el Proyecto Fondecyt nº 1140672 (2014-2018). 


\section{Cuadro A7}

Actividades de reducción de riesgos de desastres en Cauquenes y Panguipulli

\begin{tabular}{|c|c|c|}
\hline $\begin{array}{l}\text { Acciones para la reducción de riesgos de desastres } \\
(1=\text { si realiza, } 0=\text { ni realiza })\end{array}$ & Cauquenes & Panguipulli \\
\hline $\begin{array}{l}\text { 1. Educación ciudadana para enfrentar emergencias (por ejemplo } \\
\text { escuelas, enseñar cómo prevenir riesgos, simulacros) }\end{array}$ & 1 & 1 \\
\hline $\begin{array}{l}\text { 2. Educación ciudadana para adaptarse al cambio climático (por } \\
\text { ejemplo, educación sobre uso del agua y su conservación. }\end{array}$ & 1 & 0 \\
\hline $\begin{array}{l}\text { 3.Entrenamiento a funcionarios municipales para comportarse en } \\
\text { situaciones de emergencia }\end{array}$ & 0 & 1 \\
\hline $\begin{array}{l}\text { 4.Comunicación para ser usada en emergencias: por ejemplo, } \\
\text { sirenas, sistemas de mensajes de texto, otros. }\end{array}$ & 1 & 1 \\
\hline $\begin{array}{l}\text { 5.Difusión de información (radios, prensa, folletos, sobre planes, } \\
\text { prevención de riesgos) }\end{array}$ & 1 & 1 \\
\hline $\begin{array}{l}\text { 6.Planes de emergencia (con protocolos a seguir en situaciones de } \\
\text { emergencia) }\end{array}$ & 0 & 1 \\
\hline $\begin{array}{l}\text { 7.Planes preventivos de adaptación al cambio climático (por ejemplo, } \\
\text { para conservar el agua, mapeo de ríos) }\end{array}$ & 0 & 0 \\
\hline $\begin{array}{l}\text { 8. Obras de infraestructura para disminuir riesgos de desastres } \\
\text { (ejemplo en planos de inundación por lluvias o ríos, obras para } \\
\text { almacenar aqua) }\end{array}$ & 0 & 0 \\
\hline $\begin{array}{l}\text { 9.Equipamiento especial para emergencias: computadores y software } \\
\text { especializados, radios, vehículos. }\end{array}$ & 1 & 1 \\
\hline 10. Monitoreo (agua, temperaturas, riesgos) & 0 & 1 \\
\hline 11.Convenios de colaboración con organizaciones e instituciones & 1 & 1 \\
\hline $\begin{array}{l}\text { 12.Actividades de prevención con organizaciones de voluntariado } \\
\text { (por ejemplo elaboración de mapas de riesgo, educación, formación } \\
\text { de monitores) }\end{array}$ & 1 & 1 \\
\hline $\begin{array}{l}\text { 13.Actividades de prevención con organizaciones sociales (por } \\
\text { ejemplo elaboración de mapas de riesgo, educación, formación de } \\
\text { monitores) }\end{array}$ & 0 & 0 \\
\hline $\begin{array}{l}\text { 14.Contratación de servicios para enfrentar emergencias (por } \\
\text { ejemplo contratistas o convenios con empresas) }\end{array}$ & 0 & 1 \\
\hline $\begin{array}{l}\text { 15.Proyectos de inversión que ayuden a reducir riesgos y generen } \\
\text { otros beneficios (empleo ingresos, empleo, otros) }\end{array}$ & 1 & 0 \\
\hline $\begin{array}{l}\text { 16.Proyectos con empresas o corporaciones que generen beneficio } \\
\text { para el sector privado (empresas, entre otros) }\end{array}$ & 0 & 0 \\
\hline $\begin{array}{l}\text { 17.Actividades institucionalizadas con la Secretaría de Planificación } \\
\text { Comunal (ejemplo, oficina de emergencia que funciona en el Secpla, } \\
\text { información de riesgos que sea usada por Sepcpla, otro) }\end{array}$ & 0 & 1 \\
\hline $\begin{array}{l}\text { 18. Actividades de emergencia en varios departamentos del municipio } \\
\text { (por ejemplo en DOM, Dideco y Secretaria Municipal }\end{array}$ & 0 & 1 \\
\hline $\begin{array}{l}\text { 19.Participación de oficina de emergencias o sui equivalente en } \\
\text { instancias de coordinación municipal (comités técnicos de directores } \\
\text { de departamentos u otra instancia donde haya actividad de } \\
\text { coordinación regular) }\end{array}$ & 1 & 1 \\
\hline $\begin{array}{l}\text { 20.Interacciones regulares con el Concejo Municipal (por ejemplo } \\
\text { comisión de estudio del Concejo Municipal, asistencia a reuniones del } \\
\text { concejo) }\end{array}$ & 0 & 1 \\
\hline Índice (proporción) & 0,5 & 0,7 \\
\hline
\end{tabular}

Fuentes: Elaboración propia con entrevistas semi-estructuradas aplicadas a funcionarios responsables del medioambiente (junio y agosto 2014) por el Proyecto Fondecyt nº 1140672 (2014-2018). 


\title{
Resumen
}

Facilitadores institucionales y sociales para la gobernanza de los riesgos medioambientales en la escala local. Análisis con municipios chilenos

El contexto latinoamericano de exposición a riesgos medioambientales demanda un mayor entendimiento de los factores institucionales que tienen impacto en la gestión medioambiental local. Con el apoyo de métodos mixtos de investigación, este estudio examina hipótesis sobre relaciones entre factores políticos, institucionales, sociales y la gestión medioambiental municipal, en el contexto empírico de municipalidades chilenas. Los resultados sugieren que la combinación de factores políticos, arreglos y capacidades institucionales, y relaciones con la sociedad explican diferentes comportamientos municipales.

Palabras clave: riesgos medioambientales; municipalidades; instituciones y sociedad

\begin{abstract}
Institutional and social enablers for governance of environmental risks at the local scale. Analysis of Chilean municipalities
\end{abstract}

The Latin American context of exposure to environmental risks demands a better understanding of the institutional factors that impact on local environmental management. Supported by mixed research methods, this study examines hypotheses on relationships between political, institutional, and social factors and municipal environmental management in the empirical context of Chilean municipalities. The results suggest that the combination of political factors, institutional arrangements and capacities, and relationships with society explain different municipal behaviors.

Keywords: environmental risks; municipalities; institutions and society

\section{Resumo}

Facilitadores institucionais e sociais para a governança dos riscos ambientais à escala local. Análise de municípios chilenos

O contexto latino-americano de exposição a riscos ambientais exige uma melhor compreensão dos fatores institucionais que têm impacto na gestão ambiental local. Com o apoio de métodos de pesquisa mista, este estudo examina hipóteses sobre as relações entre fatores políticos, institucionais, sociais e gestão ambiental municipal no contexto dos municípios chilenos. Os resultados sugerem que a combinação de fatores políticos, arranjos e capacidades institucionais e relacionamentos com a sociedade explicam diferentes comportamentos municipais.

Palavras-chaves: riscos ambientais; municípios; instituições e sociedade

\section{Résumé}

Les facilitateurs institutionnels et sociaux pour la gouvernance des risques environnementaux à l'échelle locale. Analyse de municipalités chiliennes

Le contexte latino-américain de l'exposition aux risques environnementaux exige une meilleure compréhension des facteurs institutionnels qui ont une incidence sur la gestion environnementale locale. À l'aide de méthodes de recherche mixtes, cette étude examine les hypothèses sur les relations entre facteurs politiques, institutionnels, sociaux et gestion environnementale municipale dans le 
contexte empirique des municipalités chiliennes. Les résultats suggèrent que la combinaison de facteurs politiques, d'arrangements institutionnels et de capacités et de relations avec la société expliquent différents comportements municipaux.

Mots-clés: risques environnementaux; municipalités; institutions et société

Artículo sometido para publicación el 7 de novembro de 2015. Versión final aprobada el 28 de agosto de 2017. 